Scientił studia, São Paulo, v. 6, n. 1, p. 43-81, 2008

\title{
st \\ Desencantamento da modernidade e da pós-modernidade: diferenciação, fragmentação e a matriz de entrelaçamento
}

\author{
Terry ShinN
}

\begin{abstract}
茴
RESUMO

Em muitos setores significativos, mudou apreciavelmente o tom e a substância do discurso sociológico sobre o passado, o presente e o futuro da cultura em geral, sobre as instituições, o conteúdo das aspirações e relações individuais, e também sobre a matéria e a organização da ciência, da tecnologia e da epistemologia. O discurso da sociedade pós-moderna e, correspondentemente, os fenômenos de suporte intelectual e social oferecem algum crédito para os argumentos de que o mundo de hoje e os prospectos de amanhã estão em contraste radical, e mesmo em assimetria, com o mundo dos últimos dois séculos e meio. O propósito deste artigo é triplo. Primeiro, é necessário identificar os domínios específicos nos quais as alegações pós-modernas diferem das noções dominantes da representação moderna da sociedade e da ciência. Quais são as maneiras pelas quais a pós-modernidade forja conceitos substitutos e repudia conceitos da modernidade ou, de modo alternativo, até que grau procura-se construí-los em vista das recentes mudanças cognitivas, tecnológicas e sociais, mesmo se situando, todavia, no interior do quadro referencial da modernidade? Segundo, o que constitui a mensagem fundamental, cultural e cognitiva, da pós-modernidade? Em que tal mensagem rompe autenticamente com a modernidade e onde ela procura distintamente destruir os próprios fundamentos do pensamento da modernidade? Quais são as implicações putativas para a ciência, a tecnologia e a própria epistemologia? Finalmente, proporse-á aqui uma alternativa à análise pós-moderna, uma alternativa que depende de características básicas do pensamento moderno e que, entretanto, incorpora eventos que transformaram inegavelmente o homem, a máquina, o material e a epistemologia nas últimas décadas e que, desse modo, redesenha o mapa da modernidade especificando as componentes e os modos de interação e extensão alternativos. Essa hipótese pode ser vista como uma ponte entre a modernidade clássica e a pós-modernidade, e também como um desvio em relação a estas. Essa linha de pensamento pode ser, por ora, grosseiramente rotulada de "pós-pós-modernidade". A hipótese está baseada em uma "matriz de entrelaçamento", a qual mobiliza três noções fundamentais que são fortemente informadas pela experiência contemporânea na ciência e na tecnologia, embora não exclusivamente por esses domínios. O lugar central atribuído aqui ao conhecimento e à epistemologia não é despropositado, em vista de sua primazia no fluxo da ação hodierna (na inovação, na vida diária, na política).
\end{abstract}

Palavras-chave $\bullet$ Pós-modernidade. Modernidade. Weber. Lyotard. Latour. Jameson. Beck. Gibbons. Durkheim. Matriz de entrelaçamento. 


\section{INTRODUÇÃO}

Em muitos setores significativos, mudou-se apreciavelmente o tom e a substância do discurso sociológico sobre o passado, o presente e o futuro da cultura em geral, sobre as instituições, o conteúdo das aspirações e relações individuais, e também sobre a matéria e a organização da ciência, da tecnologia e da epistemologia. É correto dizer que, em alguns casos, observações sérias estão subjacentes a essa transformação discursiva e que, até mesmo com muita freqüência, é possível interpretar eventos selecionados, ou características restritas de eventos selecionados, em apoio a uma tese de mudança radical da sociedade e do conhecimento contemporâneos. O discurso da sociedade pós-moderna e, correspondentemente, os fenômenos de suporte intelectual e social oferecem algum crédito para os argumentos de que o mundo de hoje e os prospectos de amanhã estão em contraste radical, e mesmo em assimetria, com o mundo dos últimos dois séculos e meio. Muitas prescrições pós-modernistas conduziriam à conclusão de que a auto-interpretação, o auto-monitoramento e a auto-legislação de nossa época deslocam e destroem formas prévias de representações e interações sociais, e de que elas alteram totalmente o conteúdo, a organização e a epistemologia do trabalho científico e tecnológico (cf. Scott, 1997).

O propósito deste artigo é triplo. Primeiro, é necessário identificar os domínios específicos nos quais as alegações pós-modernas diferem das noções dominantes da representação moderna da sociedade e da ciência. Quais são as maneiras pelas quais a pós-modernidade forja conceitos substitutos e repudia conceitos da modernidade ou, de modo alternativo, até que grau procura-se construí-los em vista das recentes mudanças cognitivas, tecnológicas e sociais, mesmo se situando, todavia, no interior do quadro referencial da modernidade? Segundo, o que constitui a mensagem fundamental, cultural e cognitiva, da pós-modernidade? Em que tal mensagem rompe autenticamente com a modernidade e onde ela procura distintamente destruir os próprios fundamentos do pensamento da modernidade? Quais são as implicações putativas para a ciência, a tecnologia e a própria epistemologia? Finalmente, propor-se-á aqui uma alternativa à análise pós-moderna, uma alternativa que depende de características básicas do pensamento moderno e que, entretanto, incorpora eventos que transformaram inegavelmente o homem, a máquina, o material e a epistemologia nas últimas décadas e que, desse modo, redesenha o mapa da modernidade especificando as componentes e os modos de interação e extensão alternativos. Essa hipótese pode ser vista como uma ponte entre a modernidade clássica e a pós-modernidade, e também como um desvio em relação a estas. Essa linha de pensamento pode ser, por ora, grosseiramente rotulada de "pós-pós-modernidade". A hipótese está baseada em uma 
"matriz de entrelaçamento", a qual mobiliza três noções fundamentais que são fortemente informadas pela experiência contemporânea na ciência e na tecnologia, embora não exclusivamente por esses domínios. O lugar central atribuído aqui ao conhecimento e à epistemologia não é despropositado, em vista de sua primazia no fluxo da ação hodierna (na inovação, na vida diária, na política).

Será aqui sugerido que o sistema de entrelaçamento da pós-pós-modernidade incorpora três princípios centrais. (1) A unidade operacional da matriz de entrelaçamento consiste de um "referente" que se define por uma forma específica de ação distinguível de referentes alternativos, forma essa que possui fronteiras, é auto-referente e que encerra um núcleo estável, porém maleável à mudança e aberta à recombinação com outros referentes. (2) A matriz de entrelaçamento possui uma lógica dominante de circulação de idéias, materiais e pessoas entre os referentes, provocando, desse modo, a recombinação, a qual altera aspectos do referente inicial, ainda que esse referente genético retenha suas características originais, embora enriquecida por meio do entrelaçamento com outros referentes. O entrelaçamento de referentes não resulta em um híbrido. Em vez disso, origina uma malha dinâmica de componentes identificáveis de colaboração e de sinergia que são historicamente enraizados. (3) Referentes entrelaçados podem estabilizar-se e, desse modo, chegar a constituir territórios mais amplos. Territórios com base no entrelaçamento contêm simultaneamente a substância e a marca de seus múltiplos referentes nucleares fundamentais. Todavia, os territórios constituem extensões que adquirem cumulativamente novas características. O território de entrelaçamento expressa, assim, seus componentes referenciais autônomos e constitui as formas de ação, de conhecimento ou de epistemologia que é mais do que a adição de suas unidades fundamentais. Os territórios entrelaçados não são necessariamente permanentes e, algumas vezes, estão sujeitos a uma existência provisória ou ao sucesso e à estabilidade moderados, seguidos de dissolução. Argumentarse-á que a ciência, a epistemologia e também os processos e estruturas da globalização são mais bem entendidos como uma matriz de entrelaçamento do que nos termos oferecidos pela reflexão da pós-modernidade ou pela perspectiva da modernidade clássica.

\section{Ecos DA “MODERNIDADE”}

A modernidade anunciou o fim do sagrado que marcava a pré-modernidade - a sacralidade da crença na salvação e o espírito de pertinência e coesão da comunidade. $\mathrm{Na}$ modernidade, esse embasamento existencial do pensamento e da conduta individual e coletiva dá lugar a um zeigeist de "desencantamento" e de "gaiola de ferro", 
tão eloqüentemente expresso por Max Weber como metáfora para a modernidade (cf. Scott, 1997; Weber, 1993). ' Seis conceitos centrais estão na base do que veio a ser conhecido como "modernidade": a epistemologia racional crítica, a "universalidade", o ideal iluminista de progresso, a diferenciação estrutural, a integração funcional e o determinismo (cf. Habermas, 1987). A partir desses princípios, segue-se uma plêiade de instituições acessórias, de formas de interação social, um tipo de conhecimento e um sistema epistemológico dominante para estudar o mundo material e social, experienciando-o e nele vivendo.

A modernização incorpora duas tradições que, em certa medida, reforçam-se reciprocamente: a corrente "emancipatória" e a corrente "tecnológica". São exemplos emblemáticos da corrente emancipatória a Revolução Francesa e a declaração de autodeterminação para todos, feita pelo presidente Woodrow Wilson em 1917, a qual se tornou depois efetiva com o Tratado de Versailles. O componente emancipatório da modernização foi encarnado no Estado-nação, o qual introduziu os princípios de cidadania, dever, burocracia, direitos e responsabilidades institucionais e, não menos importante, de fronteiras. Estas últimas são as do Estado-nação, construídas em torno da linguagem, da geografia, da história, da cultura e da política. A centralidade da fronteira estende-se similarmente para a classe, a profissão, a etnia, a diversidade mental ou sexual, o privilégio e a obrigação. Embora a modernização emancipatória exaltasse o individualismo, esse tipo de individualismo era amplamente padronizado e estritamente monitorado e disciplinado. Novamente, a doutrina weberiana da burocratização do Estado-nação assegurava o consentimento ou, quando requerido, as sanções. Com efeito, um sistema demarcado pela diferenciação estrutural e pela integração funcional. É correto ver a modernidade como um sistema de reações institucionais e individuais definido por fronteiras. A modernidade é um sistema diferenciacionista. Tal diferenciação dominou as atividades internas do Estado-nação e igualmente abasteceu a tendência de grande expansão em direção à aquisição colonial, sempre que a emancipação não fosse seriamente aplicada. Partidos políticos, tanto conservadores como liberais, esforçaram-se durante décadas para sustentar essa fronteira diferenciacionista traçada pela modernidade, enquanto as iniciativas do socialismo procuraram ulteriormente torná-la mais palatável a uma base social mais ampla (cf. Stein, 1995).

A partir do cenário iluminista da modernidade, o componente tecnológico desenvolveu-se paralelamente à corrente emancipatória. Durante a segunda revolução industrial e, mais claramente, no início do século xx, sua lógica e ramificações sociais eclip-

1 A. Scott considera que a metáfora "gaiola de ferro" foi traduzida incorretamente do alemão e que o termo "habitação de aço" é mais apropriado. Scott sugere que o uso do último termo revisaria moderadamente nosso entendimento da percepção que Weber assume da modernidade. 
saram, de modo geral, os impulsos em direção às ambições emancipatórias da modernidade. Um exemplo emblemático dessa ascendência é a obtenção, por parte das escolas técnicas alemãs, em 1900, do privilégio de oferecer o grau de doutor em ciência e em engenharia. Isso significou um enorme ganho simbólico para a tecnologia, sua produção industrial e seu modo de vida, em detrimento do sistema universitário filosoficamente orientado de educação superior. Ecoando a emancipação, o braço tecnológico está baseado na racionalidade, na universalidade, na diferenciação estrutural e na integração funcional. A ciência junto com a tecnologia constitui o foco essencial. ${ }^{2}$

Na modernidade, a tecnologia expressa três imperativos inevitáveis. Primeiro, a tecnologia significa arregimentação numa escala jamais vista, o que contrasta totalmente com a maioria dos ofícios pré-modernos ou mesmo com as antigas atividades manufatureiras. O trabalho e os trabalhadores devem ser arregimentados, disciplinados e as tarefas transformadas em funções e integradas. A máquina tornou-se a palavra-chave para a tecnologia moderna. A configuração das fronteiras foi aqui central, estendendo-se à ciência, às disciplinas científicas e à comunicação entre elas, na mesma medida que à produção tecnológica. Segundo, a tecnologia estava ligada à ideologia comteana do progresso científico e humano. Esse conceito de progresso inevitável tinha sido inicialmente enunciado, no final do século xviı, por Condorcet com referência ao conceito de progresso humano; assim, a filosofia de Condorcet e de Comte fundiram-se para tornar-se uma peça central da modernidade. Para Weber, esse amálgama de progresso técnico inevitável, o qual se estende para sempre e é fomentado pela força implacável da burocracia, aprisiona o homem em sua "gaiola de ferro". O desencantamento do indivíduo deriva da falta de perspectiva, do fracasso ou da desesperança na felicidade devido a certos progressos agressivos da máquina tecnológica. Porque a espécie humana nunca pode esgueirar-se no passado, nem perscrutar seu destino futuro, não há lugar seja para o desencantamento, seja para a esperança perplexa. Terceiro, a tecnologia reduziu a margem de liberdade do indivíduo. Embora a modernidade represente um avanço nos direitos e deveres individuais, os espaços da liberdade e da liberação estão limitados, na modernidade, pelos imperativos da universalidade homogeneizadora, pela racionalidade inconstante e pela integração e

2. Seria incorreto considerar que as correntes emancipatória e tecnológica da modernidade não eram complementares em alguma medida e em alguns contextos, e até mesmo que não estavam em conluio. Na França do início do século XIX, o estabelecimento da Escola Politécnica e a introdução do sistema integrado das Grandes Escolas serve para a ciência, para a tecnologia, para o aparato militar, para a indústria e, com freqüência, acima de tudo, para a burocracia estatal. A burocracia estatal demonstra a interação sutil e poderosa entre as duas correntes da modernidade (cf. Shinn, 1980) - a emancipatória e a tecnológica -, que são comumente representadas como pólos antagônicos e em competição, dos quais a tecnologia finalmente emerge vitoriosa. Uma exploração mais profunda acerca da relação histórica entre as duas correntes requer pesquisa rigorosa. 
funcionalidade tecnologicamente impostas. A obediência e o alinhamento constituem o âmago da hierarquia, a qual, por sua vez, constitui o fundamento da burocracia tecnológica e civil.

O determinismo é onipresente. Ele contém o fundamento para a lógica do progresso humano inevitável. Leis deterministas estão no centro das epistemologias do conhecimento científico e da tecnologia. As trajetórias sociais, intelectuais, civis e mesmo pessoais do indivíduo são também a conseqüência de forças deterministas que fecham certas vias enquanto abrem outras. A modernidade é, assim, um sistema marcado pela causalidade e por fronteiras. Não se sugere aqui que a modernidade é um sistema totalmente fechado ou estático, pois a transformação está incorporada no conceito de progresso. Todavia, o mapa do progresso se realiza confinado aos princípios lineares e inexoráveis da modernidade.

Na metade do século xx, e mesmo antes, a lógica modernista da produção taylorista difundiu-se entre os países desenvolvidos. Os indivíduos buscavam a aquisição de produtos adicionais e inovadores de modo mais impulsivo do que, em muitos casos, a emancipação. Mostravam-se, assim, prontos para traduzir as complexidades do início da modernidade, a qual possuía um lado emancipatório e um lado tecnológico, em preferência por mercadorias e pelo crescimento do capitalismo a qualquer preço. Certamente, isso não pode impugnar os ganhos da maior expectativa de vida, da melhor saúde, do maior conforto, do trabalho menos fisicamente penoso, do maior lazer etc. O homem tornou-se o servo da tecnologia, e esta e tudo o que a ela se conecta representam, por sua vez, a multiplicação da diferenciação e das fronteiras.

\section{As vozes DA Pós-MODERNIDADE}

A mensagem da pós-modernidade é definitivamente menos consensual e homogênea do que as descrições e análises da modernidade. Existem numerosas nuances e sutilezas analíticas nos escritos pós-modernos. Há, todavia, concordância quanto a algumas proposições centrais. Mas, ao mesmo tempo, é possível perceber considerável trabalho desviacionista, a maioria do qual poderia ser considera, não obstante, como o pensamento de compadres pós-modernos. Ainda mais, umas poucas figuras, comumente consideradas como centrais para a visão pós-moderna, estão atualmente sendo reexaminadas e, de fato, estão afastadas dos princípios pós-modernos. ${ }^{3}$

3 Paul Veyne (2008), em seu recente livro, desconsidera a alegação de que Michel Foucault figura entre os anti-estruturalistas. Segundo muitos defensores da pós-modernidade, Foucault está no centro da inspiração pós-moderna. 
De onde provém a reflexão preliminar da pós-modernidade? O estudante com discernimento em história da ciência certamente perceberia a pós-modernidade pressagiada no clássico artigo de Paul Forman, publicado em 1971, o qual examina as origens e a dinâmica da não-causalidade na física da República de Weimar. Durante os anos 1920, muitos eminentes cientistas alemães, tanto teóricos como experimentais, abandonaram a interpretação causal e determinista do comportamento dos eventos físicos microscópicos, renunciando, desse modo, a sua crença anterior de que seria possível apreender a causa dos eventos. Na medida em que os fenômenos atômicos podiam ser descritos, as forças subjacentes eram não-causais. Esse mesmo movimento em direção à não-causalidade e de afastamento em relação ao determinismo anterior estava igualmente presente na matemática intuicionista. Forman atribui essa adoção da não-causalidade e rejeição virulenta do determinismo à expansão, na Alemanha, do neo-romantismo, tal como se vê nos escritos de Spengler. Segundo Spengler, o entendimento profundo reside no livre-arbítrio do indivíduo, na intuição e na psicologia. A causalidade, o determinismo, a universalidade etc. não constituíam o modo de avançar nem na cultura em geral nem na ciência. Forman sugere que, pelo bem ou pelo mal, o neo-romantismo valorizava o espírito e a ação livres e desimpedidos do indivíduo; alimentava um novo espírito na cultura e na ciência, abrindo o caminho tanto para novas formas de ceticismo como para novos espaços de liberdade. A introdução concomitante da incerteza na vida e no conhecimento reflete claramente as dúvidas acerca da mensagem moderna padrão.

Em 2007, Forman defendeu explicitamente a pós-modernidade em um longo artigo, no qual insiste na tese pós-moderna da reversão do estatuto e significado cultural da ciência e da tecnologia (cf. Forman, 2007). Forman declara que, durante a modernidade, a ciência usufruiu de uma importância superior, enquanto que, na era pós-moderna hodierna, a tecnologia é superior. Ele repreende severamente muitos historiadores da tecnologia pelo fracasso em perceber essa inversão entre a tecnologia e a ciência como culturalmente superiores, e também por curvarem-se implicitamente diante do primado incorreto da ciência. Forman afirma que o tempo da ciência está definhando devido à falta de confiança em seu domínio. A ciência produziu incontáveis desastres. A fé pública na ciência está abalada. Além disso, a ciência está moldada em uma lógica de disciplinaridade acadêmica, em fronteiras entre universidade e empresa, na certeza epistemológica, na linearidade, no determinismo e universalidade etc., os quais não estão no mesmo passo que a descrença, o ceticismo, a complexidade (cf. Rasch, 1991), o caos e a não-linearidade da pós-modernidade. Forman, por razões não estipuladas, parece datar a primazia da pós-modernidade na cultura em algum momento por volta de 1980, mas, para outros autores, sua introdução se deu, antes, por volta da metade do século. Para todos os porta-vozes da pós-moder- 
nidade, a ciência e sua relação com a tecnologia são cruciais para o rompimento com a modernidade. Para alguns observadores, a destruição dos princípios do progresso irreversível e do bem na ciência terminou com a explosão, em 1945, da bomba atômica. Para outros, a ciência tornou-se desacreditada e a crença no progresso se colapsou na medida em que a ciência contribuiu para a produção de bens de consumo e para uma deterioração ambiental. As crises nacionais posteriores a 1945 erodiram a aceitação da crença no Estado-nação. E mais, a burocracia e a racionalidade da organização total da sociedade e do indivíduo enfrentaram um ceticismo crescente após a metade do século à medida que grupos minoritários começaram a insistir na legitimidade ou na igualdade de sistemas alternativos de epistemologia não cientificamente sustentados. A descrença na ciência e as dúvidas acerca de muitos aspectos relacionados à modernidade proporcionaram, assim, um terreno fértil para a reflexão anti-moderna e para a emergência da visão de mundo pós-moderna. A metade do século xx, com suas novas formas de cognição e de tecnologia, é também comumente associada à gênese da pósmodernidade. Pode-se citar aqui os campos da teoria do caos, da engenharia genética, da cibernética, dos estudos de não-linearidade e complexidade, do desenvolvimento e difusão do computador e da capacidade de simulação da realidade, da geração da realidade virtual, da supremacia da imagem como entretenimento - e também como um novo dispositivo epistemológico -, da comunicação global etc. (cf. Gibbons et al., 1994; Nowotny et al., 2001; Etzkowitz \& Leydesdorff, 1997). A totalidade desses novos domínios cognitivos enfatiza a indeterminação e a contingência, dois fios que perpassam todo o pensamento pós-moderno. A extensão na qual essa nova visão alternativa de mundo expressa primariamente as percepções acadêmicas de ruptura radical (e que constituem, assim, linhas de especulação amplamente interessantes) e em que medida a mensagem pós-moderna descreve acuradamente as alterações nas atitudes e ações sociais e individuais, isso está ainda para ser estabelecido por meio de pesquisa empírica, abundante, séria e metodologicamente fundada, antes que pela reflexão meramente teórica.

\section{O GRUPO GENTRAL}

Jean-François Lyotard (1924-1998) é incontestavelmente a figura mais emblemática da filosofia da pós-modernidade. Seu livro, La condition postmodern (A condição pósmoderna), publicado em 1979, foi rapidamente seguido por dois volumes adicionais que tratavam do mesmo tópico (Lyotard, 1979, 1983, 1988). A formulação de Lyotard do conceito de pós-modernidade pode ser considerada como a culminação de seu descontentamento longamente expresso com os princípios da modernidade. Ao longo da 
maior parte de sua carreira, Lyotard criticou vigorosamente a filosofia marxista, as idéias que se seguiam da Escola de Frankfurt e, em particular, Adorno. Sua defesa do que chamou "pós-modernidade" representa uma alternativa à catástrofe evidente da modernidade, que, para ele, era o Shoah que compreendia o resultado lógico e último da experiência moderna. Com efeito, porta-voz da pós-modernidade, Lyotard milita por um tipo muito diferente de ordem social e econômica do que aquela supostamente proferida pela modernidade (cf. Lyotard, 1979, nota 11). No caso de Lyotard, assim como de muitos outros filósofos e sociólogos defensores da pós-modernidade, o nascimento e subseqüente desenvolvimento do conceito expressa mais uma reação contra o que se percebe como doenças da modernidade do que constitui uma construção positiva original construída em torno de novas noções e visões. A pós-modernidade emerge comumente como um movimento baseado em "anti"-posturas; e esse é claramente o caso em Lyotard.

Lyotard protesta contra o formato da "grande narrativa" que domina o retrato modernista da história. Essa grande narrativa, ele insiste, indica falsamente que muito do que é útil na história originou-se no Iluminismo, que desde o Iluminismo a humanidade progrediu cognitivamente com rapidez, assim como em termos de liberdade, igualdade e fraternidade. A grande narrativa histórica também impôs esses valores na escala universal. Não é somente a ciência que é considerada universal, mas também os esquemas de valores e a ética da modernidade. Lyotard rejeita a alegação de que a humanidade progrediu nos séculos recentes - de que há hoje um estoque maior de liberdade do que no passado. O nazismo e o comunismo atestam esse fato.

A modernidade, na realidade, solapou a individualidade. Assim, por exemplo, Lyotard rejeita o Estado de bem-estar social, o qual alega-se constituir um grande avanço na solidariedade social, pois o indivíduo abandona a responsabilidade por seu próprio destino pessoal. Por força do Estado-nação e de seus muitos projetos de burocratização, a individualidade tornou-se uma casca vazia. Um princípio central da pósmodernidade de Lyotard é sua insistência na "diferença". Ela requer pluralismo na escolha e ação individuais. A ética universalista elimina a legitimidade da diferença individual e do pluralismo.

A posição de Lyotard sobre a ciência e a tecnologia é complexa e algumas vezes ambígua. Pode até mesmo ser julgada como ocasionalmente contraditória. A ciência contém um mal, na medida em que representa um componente fundamental do universalismo destrutivo. A ciência tornou-se uma divindade no pensamento da modernidade e é, portanto, uma fonte de fechamento. Além do mais, gerou incontáveis efeitos materiais perigosos. Assim, Lyotard tende a condenar a ciência e a P\&D (pesquisa e desenvolvimento) que se tornou a pedra angular da política e do investimento do Estado moderno. Lyotard notou que, já no processo de modernização, ocorrera uma 
aceleração incessante na inovação e nos objetos materiais; e levantou a suspeita de que a tendência de aceleração estava se tornando mais intensa na pós-modernidade. A ciência também é atacada por conter um domínio homogeneizador. Lyotard sublinha que não são novos fatos e informação que conta, mas antes o arranjo e a recombinação dos fatos. Isso requer imaginação individual - a antítese da ciência. Lyotard propõe uma alternativa para a ciência: a "tecnociência”. Ele declara que a eficácia é sempre um sub-produto e raramente emerge da pesquisa apropriada. Na pós-modernidade, a tecnociência inventaria conhecimento e produtos benéficos para a humanidade, baseados em necessidades sociais verdadeiras e não em esotéricas considerações ou em resultados potencialmente danosos. Ele considera a tecnologia como superior à ciência e que a condição pós-moderna seria caracterizada por ela e por suas produções. A ciência devia ser dirigida pela tecnologia. Alternativamente, tecnologia e ciência deveriam ser interdependentes e indissociáveis. Lyotard, no entanto, também mantinha-se cauteloso, se não até mesmo cético, em relação à tecnociência, que ele via como tornando-se eventualmente excessiva e como restringindo a liberdade, tal como a própria ciência havia feito na modernidade.

A epistemologia racional é severamente criticada, pois faz parte da burocracia, do Estado-nação, da ciência e do mito do progresso. A racionalidade é inaceitável porque ela consiste em uma posição standard bi-polar limitada - sim ou não, válido versus inválido. Ele prefere uma multiplicidade de veículos de raciocínio que se estendem para além da racionalidade mutilada. Lyotard dá grande valor à imaginação individual. Ele considera que a modernidade, com muita freqüência, censurou a imaginação e, desse modo, negou a capacidade dos indivíduos para a criatividade e a autorealização. Sua esperança era que a cega racionalidade mecânica fosse substituída pelo pensamento analógico dirigido pela imaginação. Ele vê isso como uma via epistemológica suplementar para a emancipação do individualismo.

Grande parte da mensagem pós-moderna de Lyotard está baseada na anti-diferenciação. Ao rejeitar a epistemologia racionalista, com suas regras, seus métodos, seus processos válidos e a distinção de abordagens alternativas do pensamento, ele efetivamente apaga importantes fronteiras centrais. Lyotard recusa-se a distinguir entre modos de pensamento diferentes, a diferenciá-los. Ele repudia similarmente as fronteiras entre a ciência e a tecnologia. Aqui, a anti-diferenciação talvez seja mais manifesta e significativa. Na defesa do individualismo extremado e da multiplicação de identidades no interior de um mesmo domínio, a realidade pessoal fragmenta-se e se dissolve. A noção de grupo social e de coletivo desmorona; o que equivale à fluidez sem fronteiras. Finalmente, a unidade definida da universalidade dá lugar a uma multiplicidade desenfreada, onde, uma vez mais, os limites do múltiplo são intencionalmente confusos e móveis. O mundo pós-moderno de Lyotard é um mundo de infinitas 
combinações e re-combinações constantemente em fluxo. A diferença infindável constitui um conceito-chave, pelo qual tudo é imaginado e pelo qual o anti-diferenciacionismo caracteriza o pensamento e a ação.

Frederic Jameson é um segundo pensador pós-moderno eminente. Ele pertence à escola marxista de pensamento e vê a tecnologia e a economia como os motores da mudança cultural (cf. Jameson, 1984). Jameson considera o capitalismo contemporâneo como sendo pós-moderno em seu modo de produção e em suas relações sociais. O capitalismo inicial, aquele do Iluminismo e de parte do século xıx, foi marcado pela máquina a vapor. O capitalismo médio representou a era do colonialismo, e a ele pertencia o motor de combustão interna, o fordismo etc. O capitalismo recente, ou atual, é uma forma de capitalismo monopolista - na qual a tecnologia característica é eletrônica e nuclear -, marcada por novos modos de produção e configurações culturais.

Jameson argumenta que a cultura pós-moderna pode ser distinguida por três elementos: (1) uma perda de profundidade individual-hoje as pessoas são muitas coisas e estão constantemente mudando, o que não significa superficialidade mas, antes, multiplicidade; (2) o anterior entendimento progressivo e linear da história está perdido - os indivíduos vivem agora o presente; as noções de espaço e tempo são bastante diferentes na pós-modernidade em comparação com a modernidade; (3) a emoção é legítima e central na pós-modernidade - a emoção abre caminho para muitas outras formas de exploração e de identidade.

Jameson centra-se em dois aspectos do pós-moderno. O capitalismo monopolista assenta na empresa multinacional, transformando o modo de produção e de distribuição. A inovação tecnológica é superior nesse sistema. A aceleração já era um componente profundamente enraizado na modernidade e o ritmo da aceleração aumentava à medida que a modernidade avançava. Jameson argumenta que a empresa multinacional e as novas tecnologias - eletrônica e nuclear - tornarão ainda mais rápido o tempo da inovação e do capitalismo. Com efeito, a aceleração em todas as coisas, tanto materiais quanto pessoais, é subjacente à pós-modernidade. Jameson não prevê limites para esse mecanismo central da aceleração pós-moderna. Ele analogamente declara o fim do Estado-nação, o qual se curvou ainda mais profundamente diante do maior poder do capital (cf. Castells, 1996). A pós-modernidade modifica nossa percepção do espaço; ela se desenrola em escala global, enquanto as localidades se misturam e desaparecem, convergindo à medida que se tornam a unidade global - o que novamente elimina a nação.

As mudanças na noções de tempo e de espaço proporcionam o ambiente para a emergência de uma nova forma de individualidade e de uma nova economia. Jameson refere-se à possibilidade de uma "economia cultural", que implica uma postura alternativa em relação ao trabalho e ao consumo. Do mesmo modo, essa economia cultural 
injeta um desejo pela estética na arena cultural. À medida que o sujeito individual anterior é substituído por um indivíduo auto-operante em uma nova dimensão temporal e espacial, virão à tona recursos insondáveis da imaginação e da criatividade. Jameson, desse modo, vê o capitalismo monopolista pós-moderno não meramente como um novo modo de produção, mas igualmente como o motor para uma nova forma de identidade.

Diferentemente de outros pós-modernos, Jameson não abandona inteiramente a determinação em favor da contingência. Suas predileções marxistas impedem que isso ocorra, na medida em que ele se aferra teimosamente ao conceito de força diretora da economia e à relevância dos modos de produção. Jameson, no entanto, põe em perigo o pensamento marxista puro, na medida em que rapidamente se desfaz de outras categorias de diferenciação e, em particular, de fronteiras. Ele diz muito pouco acerca das divisões de classe na era pós-moderna, e mesmo ignora as fronteiras entre empresas multinacionais concorrentes. Jameson se regozija pela morte das fronteiras (políticas, econômicas, civis), as quais, por toda a modernidade, colocaram nação contra nação. A diferenciação institucional e as divisões de trabalho enveredam pelo mesmo caminho. Jameson funde implicitamente a tecnologia e a ciência, deixando de notar suas especificidades ou as transversalidades que permitem a travessia das fronteiras entre elas, e ainda entre elas e outras formas de organização e ação sociais. Além disso, para Jameson, o local simplesmente desaparece. A globalização não é problemática e, portanto, não há tensão ou estranhamento na justaposição de uma unidade global universal a uma unidade local particular. As fronteiras e a diferenciação desaparecem completamente do aparato conceitual dos pós-modernos.

Para os estudiosos da filosofia, história e sociologia da ciência e da tecnologia e, com efeito, para a totalidade da comunidade acadêmica e para o público em geral, o nome de Bruno Latour rima com pós-modernidade; o que é, em certos aspectos, um paradoxo. Em seu livro Nous n'avons jamais été modernes (Jamais fomos modernos), de 1997, Latour nega a existência mesma da modernidade, tornando-se ilógico para ele ser um "pós-moderno", apesar de, com toda certeza, ele o ser (cf. Latour, 1997). Latour oferece uma resposta sofisticada. Ele argumenta que a "modernidade" nada mais é do que um mito social, uma conveniência política, econômica e social de auto-representação que se desenvolve propositadamente para um período, ao qual, entretanto, não corresponde uma ordem social ou cognitiva. Com efeito, como ele mesmo escreve, "jamais fomos modernos". Visto a partir dessa perspectiva, tem pouca conseqüência o debate corrente, comumente bastante inflamado, sobre a modernidade e a pós-modernidade. Para Latour (1997), eventos múltiplos, interações e contingências estão conectados a inúmeras flechas de tempo. Nunca existiu qualquer linearidade, ordem, 
estrutura e função históricas. O próprio homem inventou um discurso chamado "modernidade", mas esse discurso está separado da dinâmica e dos eventos experienciados pela humanidade. Em particular, Latour ataca o mito da modernidade que gerou categorias de objetos e de relações, e que então procurou artificialmente entender os eventos e a identidade no interior desse falso sistema referencial. Para Latour, o ponto central é apreender que as fronteiras não existem fora da linguagem, que a "verdade" é um mito ficcional e que a força diretiva dos eventos é política (cf. Latour, 2003; Beck, 2003).

A contribuição pós-moderna central de Latour consiste em sua teoria do atorrede. Nessa teoria, as fronteiras são explicitamente negadas - o que é mais relevante, nega-se a distinção entre natureza e cultura. A natureza não existe independentemente da cultura que a produz. A natureza é o resultado de dados e sinais gerados por máquinas inventadas pelos homens precisamente para gerar esses sinais, os quais se apresentam na forma de imagens e inscrições produzidas por homens, e de textos manipulados de feitura humana, publicados em periódicos cujo conteúdo é contaminado por manobras profissionais e políticas. A natureza é produto da cultura. Latour, juntamente com M. Callon, introduziu uma entidade que é, ela mesma, de modo variado e diverso, de feitura humana, a saber, o atuante, ao qual se atribui classicamente características não-humanas "de tipo natural". Mas na pós-modernidade de Latour, o atuante desenvolve estratégias singulares, alinha-se com os atores humanos etc. e, desse modo, a diferenciação da natureza como algo diverso da cultura é novamente contrariada. Esse apagamento da diferenciação entre cultura e natureza é caracteristicamente pós-moderno e, em lugar algum, posto de modo tão ruidoso como nos escritos de Latour e de seus discípulos.

Os preceitos modernos de causalidade e invariância também são substituídos por constructos pós-modernos de contingência. Tudo é "constructo", e as forças que subjazem à construção são a contingência. A substância das construções é o "contexto". A contextualidade é tanto causa como conseqüência. Contexto e contingência dirigem o que é valorizado e avaliado como aceitável. A "verdade" é uma relação de força que resulta de um contexto específico. Um contexto alternativo resultaria em uma configuração diferente de crença e aceitação. A "verdade" pode ser definida como o que vence a batalha entre os atores em competição, o que se torna dominante (cf. Latour \& Woolgar, 1979; Latour, 1987).

Esse primado da contingência, do contexto e do poder conduz automaticamente Latour a sua bem conhecida epistemologia relativista que embasa toda sua filosofia e sociologia. Latour elimina as fronteiras entre ciência, tecnologia, especialistas e o cidadão. Como indicado acima, a demarcação entre a natureza e o estudo da natureza é banida. A natureza existe por meio dos atos dos homens. Latour igualmente bane a 
diferenciação entre ciência e tecnologia; o resultado disso é a "tecnociência”. Enquanto a tecnociência pode ser interpretada de múltiplas maneiras, ${ }^{4}$ para a pós-modernidade de Latour, a tecnologia é produzida pelo homem, e o que fornece os materiais para a ciência é uma extensão dos objetos de tecnologia feitos pelo homem. Assim, a tecnociência reforça ainda mais a anti-diferenciação de Latour (cf. Shinn \& Ragouet, 2005). Os especialistas usufruem de autoridade simplesmente devido a sua proximidade com o sacerdócio da ciência. Os especialistas não possuem conhecimento "objetivo", "legítimo". Eles são especialistas em vista de sua autoridade e essa autoridade é redobrada em virtude do mito de sua sabedoria entre os cidadãos. Latour prefere a ausência pós-moderna de fronteiras entre os cidadãos, os especialistas, os tecnólogos e os cientistas. Cada um usufrui de uma medida igual de importância. Ele insiste que a pósmodernidade exibe o realismo de reconhecer que o poder é central e que o poder da cultura opera como uma força formativa das interações humanas.

Por fim, duas publicações pós-modernas merecem ser aqui mencionadas - os escritos saídos das penas ou editados por Helga Nowotny e por Michael Gibbons (Gibbons et al., 1994; Nowotny et al., 2001). O pensamento desses pós-modernistas é bem definido e pode ser, assim, prontamente sumariado. O pós-moderno rompe com o moderno após a Segunda Guerra Mundial por meio de uma combinação de novo conhecimento científico (análise não-linear, caos e teoria da complexidade, cibernética, engenharia genética, pesquisa baseada em simulação (cf. Shinn, 2006), nanociência e nanotecnologia) e de novas capacidades tecnológicas (computadores, nova capacidade de comunicação, dispositivos de imagens para a saúde, o entretenimento e a realidade virtual). O pós-moderno é também uma conseqüência do aumento da consciência política entre os cidadãos e da demanda por mais cidadania e por inclusão nas decisões, particularmente, naquelas concernentes à direção e ao impacto da pesquisa, dos interesses diversificados de grupos bem informados. Por meio dos esforços de Nowotny e Gibbons, que possuem cargos nos centros nacionais e internacionais de elaboração de políticas científicas, o pensamento pós-moderno tornou-se a ideologia e o modo de operação do momento, altamente influentes, tendo sucesso em moldar o conteúdo de incontáveis editais para programas de financiamento público da pesquisa científica em muitas nações, na Europa e na América do Norte (cf. Shinn, 2002).

Gibbons e Nowotny descrevem a evolução da ciência e da tecnologia em termos de duas principais eras: o modo 1 e o modo 2. O modo 1, que precedeu os séculos antes de cerca de 1950, caracterizou-se pela universidade, pela diferenciação disciplinar, por um sistema de conhecimento determinado apenas pela comunidade científica e

4 Convém consultar, em particular, os dois números especiais do periódico Science in Perspective, de 2005, que tratam exclusivamente da "tecnociência". 
separado das demandas das empresas e dos cidadãos, e no qual triunfava uma epistemologia da "verdade". As formas emergentes de conhecimento e a insistência pelo público amplo por uma atenção direta da ciência sobre as questões públicas urgentes conduziram ao enfraquecimento gradual da ciência em seu formato modo 1 , ou até mesmo ao desaparecimento da ciência tal como anteriormente conhecida. Gibbons e Nowotny referem-se à verdade como uma "armadilha epistemológica". Para eles, existe de fato uma multiplicidade de vias de pensamento que se estendem para além da racionalidade clássica. Hesitam, desse modo, em relação ao estatuto da epistemologia do relativismo em sua marca de pós-modernidade. Eles afirmam a morte da teoria como um objetivo do conhecimento. O avanço teórico está presentemente exaurido. Por contraste, o futuro do conhecimento deve ser dirigido agora para a solução de problemas sociais pragmáticos urgentes, tais como o crescimento global, a destruição ambiental, a saúde e as desigualdades e carências materiais. A universidade está tornando-se esclerosada como um lugar de conhecimento. A empresa, ou uma conexão entre uma nova forma de academia e de empresa, encerra o futuro. O conhecimento é mais bem desenvolvido em conexão com a indústria e esta representa o vetor pelo qual o conhecimento prático se torna mais aplicável e se difunde pelo púbico. As disciplinas acadêmicas também estão morrendo. Elas são hoje tão diferenciadas entre si que são incapazes de enfrentar os problemas não-lineares e complexos que confrontam a humanidade. A pós-modernidade de Gibbons e Nowotny não tem fronteiras. As fronteiras disciplinares são substituídas pela interdisciplinaridade. A distância entre a universidade e a empresa é dissolvida, em vantagem da empresa. Os cidadãos não devem ser vistos ou tratados como diferentes ou alheios ao conhecimento científico. A mensagem e o conhecimento do cidadão é parte do processo da ciência; novamente, a dissolução de uma fronteira antiga. Na sociedade pós-moderna do modo 2, a pesquisa será conduzida por grupos fluídos de curto prazo que atacam um problema relevante específico, resolvem o problema e, então, debandam de modo a formar diferentes combinações e re-combinações alternativas. Como declara Nowotny, na nova ágora pósmoderna, a ciência não fala mais para a sociedade, mas a sociedade, em vez disso, fala com autoridade para a ciência.

\section{Companheiros Pós-Modernos de VIAGEM?}

Existem alguns pensadores sociais que continuam os vínculos com a modernidade, que evitam os pós-modernistas e cuja reflexão e remodelação da modernidade, entretanto, convergem com tanta proximidade para o pensamento pós-moderno, que eles poderiam, de fato, ser classificados como pós-modernos mais ou menos desviantes. 
Ulrich Beck é o pensador mais proeminente desse grupo; sua posição, em um artigo de 2003, ademais de suas discussões com Latour, dá crédito à percepção de sua posição pós-moderna (cf. Beck, 2003; Latour, 2003).

Beck procura, com maior ou menor sucesso, apresentar-se como um moderno. Ele divide a modernidade em dois períodos: a primeira modernidade e a segunda modernidade. Ele pode ser considerado como o pai da segunda modernidade. Da primeira modernidade, Beck preserva suas origens iluministas e o conceito de progresso. Ele aceita similarmente o princípio da grande narrativa. A percepção que Beck tem da segunda modernidade é original em certas bases, enquanto que, em outras, ela ecoa crescentemente a postura pós-moderna expressa por Latour.

A segunda modernidade de Beck difere da primeira modernidade em três pontos essenciais. Enquanto a primeira modernidade caracteriza-se por uma epistemologia racionalista, a segunda modernidade de Beck está, por sua vez, assentada na "modernidade reflexiva" ou, no que ele alternativamente denomina "modernidade instituída" (cf. Beck, 1994, Prefácio). Não se trata de uma denúncia clara da epistemologia racional; entretanto, abre-se o caminho para epistemologias alternativas e, talvez, para o relativismo. Como será mostrado, a racionalidade, para Beck, toma essencialmente a forma da tomada de decisão política, onde indivíduos de todos os backgrounds associam seus modos de pensamento de modo a derivar conclusões e a empreender a ação. Beck insiste que a modernidade reflexiva não deve ser confundida com a reflexão moderna, pois esta última tem base individual e concentra-se na identidade e ação individuais, enquanto a modernidade reflexiva é política, coletiva, concentra-se nos problemas sociais e assume múltiplas formas. A epistemologia não é, portanto, definida, nem determinista.

Beck distingue entre as formas de ciência da primeira e da segunda modernidade. A ciência da primeira modernidade proporciona respostas para questões formuladas no interior da comunidade científica e divorciadas das necessidades das empresas e da sociedade. Por oposição, a ciência da segunda modernidade dirige a atenção aos "erros". Ela explora os problemas prementes na sociedade e no mundo material, procurando, então, resolver esses problemas. A epistemologia da modernidade reflexiva é novamente crucial aqui. A ciência não está profundamente divorciada do social ou do cidadão. Os especialistas não são apresentados como vozes de soluções e autoridade indisputáveis. Uma ciência que se dirige ao mundo a partir da perspectiva da solução de erros é inclusiva de muitas populações. Ela não fornece respostas corretas, mas antes soluções efetivas. A cognição científica é, portanto, um problema de um multi-corpo; ela é altamente política. O lugar dessa modernidade reflexiva é, com efeito, multi-institucional. A reflexividade não está nas pessoas individuais, mas nas pessoas que operam a partir do interior das instituições. A modernidade reflexiva é tanto intra 
como inter-institucional. Nesse sentido, embora mantendo a legitimidade das instituições, Beck retém uma séria conexão com a primeira modernidade.

A incerteza ocupa o lugar central do pensamento de Beck e encontra sua mais clara expressão no que ele denomina a "sociedade de risco". A segunda modernidade é, com efeito, caracterizada pela incerteza, diferentemente da primeira modernidade que se caracteriza pelo conhecimento. Beck está profundamente preocupado com os riscos que ameaçam a humanidade - riscos naturais e riscos provocados pelo próprio homem à guisa de catástrofe química, nuclear, biológica ou ecológica. As instituições reflexivas apresentam-se como um bastião contra os perigos inerentes à sociedade de risco. Instituições civis e profissionais mistas (com a circulação de informações e fatos no interior e entre as instituições) proporcionam um referencial para a mitigação do risco. Se a segunda modernidade pudesse ser reduzida a uma única idéia, ela certamente deveria ser reduzida à "sociedade de risco"; e os outros conceitos e medidas apresentados por Beck parecem ser formulados para mitigar o risco.

Uma garantia contra o risco é, assim, a reflexividade coletiva e múltipla. Beck insiste que, na segunda modernidade, as fronteiras definham. As fronteiras da primeira modernidade não estão mais presentes na segunda modernidade. E isso apesar da manutenção das instituições, pois os limites institucionais se apagam à medida que as idéias, os materiais e as pessoas passam de instituição a instituição. Essa ausência de fronteiras da segunda modernidade já conta como uma característica-chave da pósmodernidade. Aqui, a segunda modernidade assemelha-se muito à pós-modernidade, apesar das negativas de Beck. 5

A tendência mais significativa e palpável de Ulrich Beck para uma pura análise pós-moderna é visível em sua representação do problema da relação natureza/cultura. Assim como Latour e a maioria dos outros pós-modernos, Beck recusa aqui a diferenciação. Ele retira seus exemplos acerca da fusão entre natureza e cultura do domínio da ecologia e do ambiente; argumenta que a natureza não tem existência enquanto tal, que ela é um produto da cultura. Aquilo a que nos referimos inocentemente como "natureza" é uma entidade feita pelo homem. Uma floresta não é uma criatura da natureza; ela é o resultado de incontáveis intervenções humanas - desflorestamento, reflorestamento, introdução de novas espécies de animais ou de plantas, seleção de elementos

5 É interessante notar que, no trabalho de Beck, a abundância material necessária para alimentar, vestir e a abrigar a população mundial é apresentada como um dado. A prosperidade é uma pressuposição não questionada da segunda modernidade. Em nenhum lugar, levanta-se a questão da escassez ou da necessidade de lidar com essa possibilidade. A escassez é inteiramente superada pelo medo do risco. Isto está numa interessante contraposição com Drexler, cuja preocupação inicial com a engenharia molecular e a nanotecnologia era uma solução para o problema impeditivo da limitação de recursos em meio a uma população global que cresce tanto em número como na demanda. 
pelo uso de produtos químicos, queimadas etc. Em lugar algum pode-se encontrar uma floresta que não seja um produto da intervenção cultural (cf. Beck, 2003). Na pós-modernidade, o homem é a medida de tudo.

Os escritos de Scott Lash e de Anthony Giddens são, em alguns aspectos, de difícil julgamento quanto as suas posições em relação à pós-modernidade. Em alguns aspectos, eles parecem mover-se lentamente, quase relutantemente, nessa direção, enquanto, por outro lado, resistem à evolução. O caso é claro para Lash, que converge para a pós-modernidade, ainda que em uma única via e freqüentemente evitando muito do vocabulário e muitas das questões comumente associados com a pós-modernidade (cf. Lash, 1994). Os escritos de Lash contribuem com uma nova dimensão para a reflexão pós-moderna. Seu principal interesse é a estética da cultura pós-moderna. Ele deseja uma forma cultural nova, marcada pela moral e pela ética. Essa estética toma a forma da conduta individual e também de uma nova liberdade em direção à identidade e à criatividade: a arte. Em uma extensa série de publicações, Lash se concentra principalmente nas questões da identidade e do amor em uma arena que, de algum modo, parece flutuar entre o moderno e o explicitamente pós-moderno (cf. Lash, 1993; Lash \& Friedman, 1990, 1992).

Scott Lash dedica crescente atenção ao lugar da emoção na pós-modernidade. A emoção é vista como uma apreciação da identidade e como um mecanismo de autoliberação. A emoção é também vista como um mecanismo para a coletivização em face das crescentes inclinações emancipatórias auto-referentes da pós-modernidade. A emoção pode, assim, conter um meio pelo qual o entusiasmo coletivo e a solidariedade social podem ser gerados. Ela age, aqui, como uma espécie de antídoto criativo à fragmentação do eu e à fragmentação da ordem social que caracteriza a pós-modernidade. Por outro lado, ela pode funcionar como uma faca de dois gumes. O sentimento de um alto grau de emoção pode induzir a uma disposição de excitação, energia e concentração social que, por sua vez, injeta uma ambiência de re-encantamento. Contudo, em vista das características fragmentadas, de anti-diferenciação, de auto-monitoração, de auto-interpretação e de auto-legislação da pós-modernidade, a temporalidade e os efeitos construtivos da emoção serão, em pouco tempo, ou esquecidos ou traduzidos em um desencantamento re-fortificado. ${ }^{6}$

6 Quero aqui agradecer a Anne Marcovich por chamar minha atenção para a capacidade de "re-encantamento", latente na pós-modernidade. Ela sugere que a emergência ou a manipulação da "emoção" entre as populações da pós-modernidade pode, a curto prazo, neutralizar o giro estrutural em direção ao desencantamento, normalmente associado com a modernidade weberiana. Sugerirei abaixo que o conceito durkheimiano de "efervescência" pode, sob condições específicas, servir ao mesmo propósito. Tal como insiste Anne Marcovich, a emoção deve ser, desse modo, subscrita como uma força fundamental na interação sociológica e nos eventos históricos. 
Discutirei, de modo muito breve, a posição de Anthony Giddens. Tal posição é, ao mesmo tempo, sutil e desestabilizadora. Embora tenha sido, durante longo tempo, um advogado enérgico da modernidade (cf. Luhman, 1994), Giddens, nos últimos anos, começou aparentemente a mudar. A defesa de Giddens da modernidade baseia-se na centralidade da unidade família, do Estado-nação, da sociedade de classes e das divisões de trabalho - todos conceitos e padrões modernistas. Contudo, ele percebe a mudança contemporânea nas relações constitutivas da sociedade. Estas são claramente discutidas como dinâmicas de imbricações e re-imbricações. Essa noção permite a transformação, embora sempre no interior do referencial da cultura moderna. Enquanto Giddens sustenta a centralidade moderna do indivíduo, o individualismo vai sendo suprimido pelo sistema de bem estar social. $\mathrm{O}$ individualismo perde sua tendência emancipatória por meio de pressões sociais homogeneizantes. Desse modo, esse autor, ao mesmo tempo em que defende a modernidade, percebe forças que devem finalmente conduzir a sua profunda reforma (cf. Giddens, 1991). Giddens refere-se comumente a essa iniciativa como "política emancipatória”, o que é evidente, entre outros escritos, em sua colaboração com Beck e Lash (cf. Giddens, 1994).

No entanto, a preocupação altamente informada e bastante conhecida de Giddens com o pré-moderno constitui já um bastião contra uma afinidade zelosa com os pósmodernos e, tal como já foi indicado, a enorme maioria de seus trabalhos explora a transformação contemporânea ainda no interior das fronteiras do moderno. Além disso, seu recente flerte com a pós-modernidade, tal como ilustrado por suas parcerias com Beck e Lash, representa um deslizamento na direção do que é agora uma especulação pós-moderna bastante estilística. Falta verificar se isso representa verdadeiramente uma mudança da parte de Giddens.

O veículo por meio do qual ocorre o envolvimento firme de Giddens com o prémoderno, o moderno e a modernidade cambiante liga-se à obsessão exibida por vários estudiosos com o tópico da "reflexividade". Com efeito, a especulação sobre a reflexividade é agora um dos principais princípios da sociologia e se estende para além da análise pós-moderna. Giddens foi tornando-se cada vez mais fascinado pela reflexão sobre a reflexividade e introduziu de modo crescente o tópico em seu trabalho. Se isso contribuiu para um redirecionamento mais profundo de sua análise, talvez ainda não se possa julgar completamente.

Entretanto, uma coisa é clara, a saber, a inflação da linguagem da "reflexividade" - "modernidade reflexiva", "reflexividade da segunda modernidade", "reflexividade pós-moderna", "reflexividade instituída", "reflexividade estética", a "reflexividade irrefletida" de Bourdieu e assim por diante - serve freqüentemente para obscurecer e confundir o pensamento sociológico e filosófico sobre as relações entre a pré-modernidade, a modernidade e as incontáveis formas recomendadas de pós-mo- 
dernidade. Em nenhum lugar isso é mais claro do que nos trabalhos de David Inglis e John Bones. Esses autores assumem uma postura parodoxal e, em alguns aspectos, esse paradoxo reflete-se no ensinamento comumente bastante perceptivo de Anthony Giddens. Inglis e Bones censuram corretamente Beck e seus muitos companheiros pósmodernos pelo mau uso e pelo uso excessivo do vocabulário da "reflexividade", que eles afirmam constituir pouco mais do que um tipo de categoria abrangente que serve comumente para anular ou contornar inadequações do pensamento (cf. Inglis \& Bones, 2006; Inglis, 2003, 2005). Contudo, exatamente ao mesmo tempo, Inglis e Bones insistem repetidamente que a aplicação do pensamento da reflexividade pode resolver importantes questões no confuso debate sobre a modernidade - um conceito ao qual eles aderem firmemente. Assim, a "reflexividade" parece ter emergido como uma espécie de disposição, de moda e de armadilha de jogo de palavras. Muitos caíram vítimas disso, embora Giddens não tenha sido um deles, mas seu flerte com a pós-modernidade certamente tem efeitos e não necessariamente para o melhor.

\section{UMA PITADA DE GETICISMO}

Esta seção lança dúvidas, em dois níveis, sobre a própria centralidade do debate sobre modernidade versus pós-modernidade. Primeiro, o debate mais incisivo pode não ser o debate entre a modernidade e a pós-modernidade, mas antes entre a modernidade de Émile Durkheim (1912, 1993) e a pós-modernidade (Scott, 1997). Segundo, para os países anteriormente colonizados e para as regiões em desenvolvimento, que com muita freqüência tiveram uma experiência muito superficial da modernidade, qual é a relevância da pós-modernidade ou, pelo menos, quais são os componentes da pós-modernidade que valem a pena ser mantidos?

O sociólogo Alan Scott tentou obliterar e, de fato, rejeitar o debate modernidade versus pós-modernidade por meio da sociologia de Durkheim. Scott abre seu ataque sugerindo que as teses do desencantamento burocrático e desumanizador do pensamento weberiano da modernidade são, de fato, uma construção fundamentalmente equivocada do verdadeiro significado pretendido por Weber. Scott insiste que muito da análise da modernidade volta-se para a metáfora da "gaiola de ferro", a qual foi mal interpretada por Parsons devido a um erro de tradução. Para Scott, a metáfora não é a de uma "gaiola de ferro" ("iron cage"), mas antes uma "habitação de aço" ("steel housing"). Esse deslize de tradução é essencial (Scott, 1997). O ferro é rígido, inflexível, e a gaiola

\footnotetext{
* Para um esclarecimento a respeito da tradução para o português da expressão de Weber, cf. a tábua de correspondência vocabular, elaborada por Antônio Flávio Pierucci, em Weber, 2004, p. 19-20. (N.E.)
} 
aprisiona. Ao contrário, o aço é mais resistente, capaz de desempenho em condições mutáveis. Além disso, uma habitação é um espaço relativamente aberto, no qual operam dinâmicas e no qual as coisas estão livres para mudar. Scott insiste que essa reinterpretação da metáfora-chave da modernidade conduz o pensamento moderno weberiano a um estreito alinhamento com as idéias de Durkheim sobre a dinâmica social. Durkheim mantém constantemente em equilíbrio o individual e o coletivo. Ele permanece preso entre os dois pólos, embora sempre livre em seu movimento. A posição precisa nesse cenário, argumenta Durkheim, dependerá dos requisitos de circulação para uma dada época histórica.

P. Schilling e C. Mellor introduziram posteriormente uma aproximação entre uma forma não-weberiana de modernidade e Durkheim. Esses sociólogos sublinham o conceito durkheimiano de efervescência. As pessoas estão suspensas entre a iniciativa individual e a ação coletiva; tal posição é dinâmica e cambiante. Existe um forte componente emocional na efervescência, que não nega necessariamente a racionalidade. A efervescência é de dois tipos: construtiva e destrutiva. Uma é socialmente positiva; a outra contribui para o colapso de uma sociedade. A efervescência introduz dois fatores centrais na modernidade. Ela proporciona as bases para a escolha; ela oferece igualmente a oportunidade para adaptação e para mudança. Schilling e Mellor consideram a efervescência como central para a modernidade e percebem a contribuição de Durkheim como um discernimento básico. Eles apontam que esse conceito de efervescência contorna as inevitabilidades da modernidade weberiana e, não menos que isso, evita a armadilha weberiana do desencantamento (cf. Schilling \& Mellor, 1998).

Porta-vozes de países em desenvolvimento, anteriormente colônias, também expressam constantemente reservas em relação ao que eles percebem como um objetivo mal dirigido e exagerado da pós-modernidade. Os escritos de R. Lee são exemplos típicos dessa crítica (cf. Lee, 2008). Particularmente, Lee é crítico da tese da segunda modernização, formulada por Beck, a qual ele considera como um esforço dos países do Atlântico Norte (Europa e Estados Unidos), seja para esquecer o resto do mundo, seja ainda para dominá-lo. Lee condena o fracasso da pós-modernidade em reconhecer que grande parte do terceiro-mundo nunca teve a experiência da modernização, ou quase isso. Como, então, se pode esperar que alcancem a pós-modernidade?

Lee é particularmente cético em relação à recusa da pós-modernidade em reconhecer a realidade das fronteiras e sua importância para a ação social. A eliminação das fronteiras é utópica. As fronteiras são marcas características de diferentes grupos, formas de trabalho, caminhos epistemológicos e nações. Em nenhum lugar isso é mais evidente do que nos países em desenvolvimento do hemisfério sul. Mas existe muita evidência de que as fronteiras permanecem igualmente centrais no norte, onde, entretanto, as gradações de diferença entre os componentes da ação humana refinaram-se por meio 
da multiplicação de especialidades. Para alguns observadores, esse refinamento da diferenciação obscurece a realidade determinista das fronteiras. Com efeito, alguns pósmodernistas do hemisfério norte chegaram a rejeitar as fronteiras com base em que elas impedem a comensuração, mas existe evidência crescente de que as fronteiras não bloqueiam a comensuração, pois a comunicação e a inteligibilidade recíproca atravessam as fronteiras por meio de travessias seletivas e freqüentes (cf. Espeland \& Mitchel, 1998). Os países em desenvolvimento não podem tolerar essa miopia ou má-vontade.

Lee continua atacando o próprio conceito de modernidade reflexiva ou, em outros termos, de "reflexividade instituída". Ele declara que a noção de Beck baseia-se em um falso entendimento das relações que operam entre os atores e que, além disso, Beck está inteiramente incorreto em sua dissolução da fronteira natureza/cultura, e também em suas conseqüências para a chamada modernidade reflexiva. Lee conclui que o problema não é a modernidade, mas antes certos projetos de modernização. Desse modo, Lee não anuncia "o fim da modernidade, mas antes o ceticismo em relação a certas formas de modernização"; ele conclama para a promoção do que especificamente denomina de "modernidade múltipla”.

\section{Para além da Pós-modernidade: A “MATriz de entrelaÇAmento”}

Pretende-se que o conceito de matriz de entrelaçamento seja uma crítica tanto da modernidade como da pós-modernidade, proposto como uma via que pode contribuir para transcender o que está se tornando um debate inconclusivo e cada vez mais tedioso. O conceito de entrelaçamento preserva os elementos de referente, de diferenciação, de fronteira e de divisão do trabalho. Esse conceito sustenta simultaneamente a dinâmica da circulação e a sinergia de homens, materiais e idéias por entre as fronteiras, valorizando e promovendo a comensuração. O entrelaçamento de múltiplos referentes constitui geografias territoriais ou políticas, sociais, epistemológicas e cognitivas mais complexas e inovadoras. Desse modo, o entrelaçamento constitui uma plataforma dinâmica e reversível que promove recombinações e descombinações. Antecipa, portanto, interconexões de elementos estranhos e familiares, historicamente dissociados, nas quais, entretanto, cada referente retém suas características históricas particulares, assumindo, ao mesmo tempo, novas características.

O “referente” compreende aqui a unidade básica de operação social/cognitiva. Um referente é fundado na ação. Referentes diferentes se distinguem por categorias individuadas de atividade; os referentes possuem sua própria lógica, funções, hierarquias, canais de comunicação e vias de circulação interna (cf. Abbott, 1995; Espeland \& Mitchel, 1998). Constituem referentes distintos o direito, a medicina, a ciência, a 
engenharia, a contabilidade, a arquitetura, a informática, a arte, o transporte, a publicidade, a energia etc. No interior da ciência, as diferentes disciplinas representam referentes e, no interior da medicina, o mesmo vale para as especialidades. Cada referente é determinado por uma forma particular de conhecimento, de competência, de mercado e de identidade coletiva, e cada um tem seus próprios objetivos, história e ambições. Isso pode soar como uma dinâmica de exclusão, o que constitui uma das maiores críticas aos referentes por parte da pós-modernidade. Entretanto, por sua dinâmica interna e pelo auto-interesse, os referentes são também seletivos e, ainda assim, altamente inclusivos. A matriz de entrelaçamento pretende demonstrar o caráter inclusivo dos referentes e, desse modo, pretende tanto superar a pós-modernidade como sugerir de modo mais claro as operações das interações sociais.

Dito de outro modo, o moderno sistema de referência clássico padrão costumeiramente enrijece e fecha fronteiras, segmenta a sociedade por meio do congelamento da diferenciação e das divisões de trabalho, impedindo novas configurações. Em oposição, a pós-modernidade tende a diminuir ou negar as fronteiras, rejeitando, desse modo, a existência mesma dos referentes sociais e intelectuais. A pós-modernidade mistura tudo, diminuindo normas, estrutura e função, abomina a substância, a continuidade e a historicidade, minimizando ou rejeitando a identidade de elementos que são vistos como temporários, oportunistas e sempre fluidos. A pós-modernidade recusa, assim, os referentes, de modo que, em um universo pós-moderno, tudo se torna possível e possui um igual valor. É seguro dizer que o resultado constitui um mundo unidimensional. A dinâmica é vagamente denominada "contexto" e "contingência". Entretanto, essas palavras pós-modernas pouco dizem acerca de como os componentes se unem e, menos ainda, acerca das vias e possibilidades de mobilidade e combinação.

As unidade de entrelaçamento - de fato, os referentes - podem, em alguns aspectos, ligar-se às "figurações", "figuras" ou "configurações" da sociologia de Norbert Elias (cf. Elias, 1987). A sociedade é composta por (referentes) individuais e agrupamentos que exibem qualificações, funções e coletivos específicos. Essa configuração não impede que as particularidades dos indivíduos contenham os vários referentes. Existe uma heterogeneidade de manifestações endógenas para todo referente, ainda que o referente mantenha seu próprio sistema de coordenadas - seu sistema está codificado na linguagem de Niklas Luhman. Os referentes também são informados pelo hábito, de Pierre Bordieu, para quem toda categoria social possui seu hábito particular, seu modo específico de operação e de percepção. A auto-reflexividade proporciona um sistema de coordenadas internalizado e que se auto-mantém (cf. Bourdieu, 1979).

Para esse esquema pós-pós-moderno de matriz de entrelaçamento, proposto como uma tentativa, as práticas ordinárias dos referentes são fundamentais. Primeiro, em qualquer momento histórico particular, um referente expressa suas caracterís- 
ticas endógenas, suas capacidades e coordenadas de atividade, que estão, entretanto, submetidas constantemente à mudança e ao desvio internamente gerado em virtude das contribuições originais de seus próprios subgrupos e indivíduos mais proeminentes. Assim, por meio da circulação interna, o referente não é, em si mesmo, intrahistoricamente estático, mas antes exibe um potencial para a mudança dinâmica circunscritamente imbricada. A troca e a colaboração intra-muros pode isoladamente provocar transformação; não se requer necessariamente a travessia de fronteiras, a fluidez e o input amplamente social do pós-moderno. Segundo, para um dado referente, tem lugar a circulação de indivíduos e de grupos que atravessam as fronteiras dos referentes, seja pela circulação de curta-duração, seja por uma imersão prolongada nas comunidades referentes alternativas, as quais possuem competências, mercados e, algumas vezes, hábitos alternativos. Esse entrelaçamento pode ser espasmódico ou agudo. A característica importante é que o entrelaçamento contém, em graus diferentes, um padrão de dinâmica social. Ele é a substância da circulação e pode tornar-se um motor de transformação. A mudança freqüentemente ocorre quando grupos, que haviam temporariamente circulado por um referente alternativo, retornam a seu referente básico pela travessia inversa das fronteiras e enriquecem seu sistema por força do novo conhecimento, técnicas ou representações que adquiriram durante sua jornada extra-referente. Essa jornada pelo segundo referente pode mostrar-se igualmente frutífera para o referente alternativo. Um conceito central que se deve reter aqui é que tais misturas não alteram a lógica, a estrutura ou as ações fundamentais do referente básico, o qual mantém seu código genético original.

O entrelaçamento permite a transformação em um contexto de continuidade. Isso parece não implicar nem o que freqüentemente se considera como uma ridicularização da modernidade, nem uma defesa da desinstitucionalização, da identidade e da auto-negação na pós-modernidade. O entrelaçamento legitima e preserva o referente no nível individual, coletivo, profissional e institucional. Como o "referente" está fundado na ação e na atividade, as coordenadas e vias de competência, a troca e a comunicação retêm uma medida de limite racional. Uma vez que as regras podem ser alteradas, isso se faz no interior de um quadro de antecipação calculada.

\section{Feghamento E FLUIDEZ}

A rejeição pós-moderna da modernidade depende amplamente da lógica de "fechamento" desta última - diferenciações infindáveis, divisões de trabalho, fronteiras nacionais, burocratização, restrições e padronização do individual. Por oposição, os defensores da modernidade reprovam a lógica pós-moderna que nega os sistemas, as 
instituições, a diferenciação (principalmente entre cultura e natureza), a ciência, as disciplinas, e que clama pela personalidade múltipla e pelo esvaziamento do local em favor do global. Repetindo: uma lógica de fechamento versus uma lógica de fluidez.

A metáfora do "entrelaçamento" sugere uma via que pode circunscrever a polarização fechamento/fluidez. $\mathrm{O}$ entrelaçamento permite uma variedade de relações ou interações no interior e entre referentes sociais, cognitivos e epistemológicos, nas quais os referentes podem (i) sobrepor-se pouco ou muito, (ii) se co-misturar ou (iii) incluir um entrelaçamento por inserção. Cada um desses arranjos constitui um grau, maior ou menor, de entrelaçamento.

No entrelaçamento por sobreposição, alguns componentes de vários referentes são reconhecidos como coincidentes e são compartilhados; podem, assim, servir como pontes para a travessia de fronteiras, para a troca de competência ou de conhecimento, para o reconhecimento e uso combinado de métodos e representações comuns. Cada referente mantém sua identidade e posição específicas em relação ao referente vizinho, e mesmo assim emerge a circulação, práticas conjuntas e a consciência de um referente recíproco. As relações não são dadas. Os referentes podem tocar-se brevemente ou apenas deslocar-se de modo parcial em direção ao outro, sem inscrever todavia, com isso, uma marca estrutural duradoura.

O entrelaçamento por co-mistura requer a co-penetração de múltiplos referentes. Domínios específicos e definidos de elementos de cada referente são anexados aos elementos do outro referente. Aqui, a colaboração de fraco entrelaçamento por sobreposição freqüentemente se traduz em uma forma de sinergia. No entrelaçamento por co-mistura, projetos particulares selecionados, objetivos, linguagens, técnicas e representações de diferentes referentes transformam-se. As atividades ocorrem aqui em dois níveis. Em um registro, cada referente continua principalmente como antes. Ele desenvolve seus projetos, práticas e mercados de origem. As pessoas são treinadas e socializadas segundo os preceitos estabelecidos do referente. Nessa estrutura, a circulação ocorre assim como antes. Todavia, em paralelo com isso, emerge um segundo conjunto de conhecimentos, práticas e um mercado suplementar, abertos nos espaços intersticiais que habitualmente ocorrem, em diferentes graus, em todos os referentes envolvidos no ambiente do entrelaçamento por co-mistura. A fluidez faz parte desse processo. Por meio das interações sinergéticas de alguns indivíduos oriundos de referentes diferentes, pode-se produzir um novo vocabulário, uma nova maneira de fazer e de ver, e um novo mercado. Pessoas com capacidades alternativas e complementares se encontram, aprendem a construir um novo conceito, objeto, conjunto de relações sociais etc. não somente por meio da adição de suas capacidades, como ocorre no entrelaçamento por sobreposição, mas elas, de fato, dão um passo além e multiplicam suas capacidades. Um novo fluxo de troca desenvolve-se paralelamente à coexistência 
do capital tradicional de cada referente. Dito de outro modo, prêmios são oferecidos pelos adeptos de cada referente e entram em circulação. Esses prêmios são equilibrados pela oferta de contra-prêmios do referente de base. Enquanto o estoque de competência aumenta segundo uma lógica aditiva no entrelaçamento por sobreposição, ele é multiplicado no entrelaçamento por co-mistura. Isso encerra uma diferença fundamental entre as duas formas. Em alguns casos, o entrelaçamento por co-mistura pode originar uma nova comunidade (freqüentemente bastante pequena e de curta duração) e, algumas vezes, até mesmo um novo referente. É importante notar que o novo referente não colide com as operações e a autonomia dos referentes iniciais. Isso ocorre no interior de um quadro de estruturas institucionais e organizacionais estabelecidas. Contrariamente às teses pós-modernistas, aqui as fronteiras não se evaporam nem se reduzem a um mito ou a uma ficção oportunista. Coletividades, identidades, formas de fazer e de saber anteriores não precisam ser abandonadas ou jogadas fora a fim de se obter identidade, interação, representações ou visões transfiguradas.

Os arranjos de referentes por sobreposição e por co-mistura fornecem múltiplos e até mesmo simultâneos experimentos, diferenças e novas combinações, recombinações e descombinações. A freqüente demanda verbal, radical e agressiva dos pós-modernos por diversidade, diferença e multiplicidade pode ser acomodada pela perspectiva do entrelaçamento. O motivo é, em parte, a circulação e a sinergia, e está similarmente conectado à travessia de fronteiras. A multiplicação de capital e prêmios simbólicos também se mostra importante. A multiplicidade e a diferença na matriz de entrelaçamento permite o movimento. Não obstante, a fluidez não é realizada por meio do abandono e perda dos referentes. Os referentes são aqui um adjunto. Eles podem ser considerados como uma necessidade sociológica do tipo aludido por Elias e Durkheim. Mas eles não são tão obrigatórios e restritivos a ponto de colocar em risco a diversidade e a diferença psicológica, artística e das práticas e expressões institucionais. Em parte, isso deriva da lógica básica da reversibilidade do entrelaçamento. Os referentes constituem o material de um entrelaçamento. Eles também possuem a possibilidade de des-entrelaçamento. $\mathrm{O}$ entrelaçamento não é uma interconexão. Não há fechamento aqui. $\mathrm{O}$ arranjo de entrelaçamento pode ser associado ao entrelaçamento entre os dedos das duas mãos que se entrelaçam entre si. Existe espaço para movimento lateral e longitudinal. Existe também espaço para recuo e completo desengajamento, à medida que os dedos de uma mão se afastam dos dedos da outra mão. Trata-se de um potencial de conexão e de complementaridade em um ambiente de autonomia e de liberdade; o que definitivamente contrasta com as perspectivas projetadas tanto por pósmodernos sem referência como por modernos padronizadores e embrutecedores.

O entrelaçamento por inserção constitui a forma última de entrelaçamento. Indivíduos e grupos originários de um referente tornam-se habituados a um referente 
alternativo. Ao mesmo tempo em que se afastam de seu referente doméstico, tais indivíduos e grupos, não obstante, de modo constante ou intermitente, despendem considerável tempo em conexão com o segundo referente hospedeiro. Sua lógica e linguagem fundamentais permanecem aquela do referente inicial, apesar de que, pela freqüentação de um segundo referente, eles também se tornam amplamente familiarizados e, talvez, mesmo moderadamente proficientes nos modos do referente alternativo. Eles nunca se tornam uma parte ou um membro completo do referente hospedeiro, o que requer treinamento, longa experiência, um habitus, domínio dos códigos internos, conhecimento tácito e um verdadeiro incentivo para tornar o referente hospedeiro o "seu" referente primário. Assim, os indivíduos se inserem, o que não os torna, todavia, membros autênticos. ${ }^{7}$ A identidade reside no seu referente central. O envolvimento múltiplo total não ocorre. O entrelaçamento por inserção representa o alcance máximo do engajamento múltiplo. A participação da personalidade dividida e eficiente não consegue emergir. O entrelaçamento por inserção comumente proporciona vantagens políticas, sociais, materiais e epistemológicas básicas para fim de expertise, a qual não pode ser simultaneamente valorada a partir de ambos os referentes. Esse tipo de entrelaçamento também fornece uma base para o treinamento de pessoas que visam projetos específicos para atravessar o divisor referencial. No final da carreira, indivíduos freqüentemente afastam-se do referente hospedeiro e perdem subseqüentemente seu valor como guardiães de seu referente original.

Para os pós-modernos, a dinâmica do entrelaçamento por inserção deveria proporcionar diversas lições e demonstrar as condições limites de suas propostas. A expertise autêntica e completamente múltipla, o engajamento institucional ou de grupo, ou mesmo a personalidade múltipla, ultrapassam aquilo que é efetiva e tecnicamente possível, coerente, temporal e organizacionalmente realizável por qualquer indivíduo. Não faz absolutamente sentido postular que o humano não conhece limites. A tendência pós-moderna em direção ao múltiplo é um poço sem fundo; está além do ideal renascentista polivalente. A necessidade de poder em um mundo de especialidade constitui uma flagrante contradição insuperável para a ultra-multiplicidade que é almejada pelo pós-moderno sob o imponente termo "diferença”. A segunda lição a ser retirada pelos pós-modernos do entrelaçamento por inserção assume o juízo oposto,

7 Para o conceito e detalhes dos problemas envolvidos em tornar-se um membro autêntico de um referente hospedeiro, quando se tem origem em referentes diferentes, cf. Shinn \& Lamy, 2006. A informação apresentada nessa análise concentra-se em problemas de entrelaçamento por inserção para cientistas pesquisadores do CNRS que abriram uma empresa enquanto empreendedores, mas que nunca tiveram sucesso em evoluir como "verdadeiros" empreendedores. Aqui, os cientistas não podem evoluir para além de um arranjo de entrelaçamento por inserção. Não se discerne aqui nem a emergência de um híbrido, freqüentemente aludido como uma configuração futura promissora na pós-modernidade, nem de um autêntico capitalista. 
em sua forma extrema. O perigo aqui é que o entrelaçamento por inserção evolua para uma interconexão estéril. O movimento desejável e a competência multi-lingüística do entrelaçamento por inserção correm o risco de tornarem-se uma armadilha, onde o ator adota regras e fórmulas rígidas de modo a encobrir situações que são definidas como estereótipos vazios de situações altamente complexas. Em vez de realizar um grau avançado de liberdade e fluidez, esse fechamento evoluiria, ao contrário, na ficção pós-moderna, vazio de participação, de criatividade, de realização e de liberdade. O hiper-entrelaçamento se voltaria, assim, contra si mesmo e tornar-se-ia, por sua vez, um turbilhão de tendências emotivas de auto-decepção e ineficiência.

\section{Dois exemplos de matriz De entrelaçamento}

O primeiro exemplo de matriz de entrelaçamento concentra-se nos entrelaçamentos por sobreposição e por co-mistura, e trata da pesquisa nas ciências físicas que envolveu aproximadamente trezentos cientistas, de modo permanente ou intermitente, seja por uns poucos anos de carreira, seja pela duração de trinta anos. Essa combinação de entrelaçamento por sobreposição e por co-mistura nunca resultou em uma nova disciplina e tampouco no estabelecimento de um instituto ou laboratório. A dinâmica pertencia totalmente a uma categoria de entrelaçamento na qual indivíduos permanecem simultaneamente ligados as suas disciplinas e institutos de origem e que se movem através de fronteiras institucionais e disciplinares de modo a explorar fenômenos novos e complexos. Esse entrelaçamento tem sido referido como "um laboratório sem paredes". O segundo episódio aqui apresentado concentra-se, de outro modo, no entrelaçamento por co-mistura e por inserção, e trata de comunidades e identidades que se movem da escala geográfica/política local para a escala global. A globalização é um tema rotineiro dos pensadores pós-modernos, embora o modo como precisamente as questões de identidade e cultura operam fique sem exame. A perspectiva do entrelaçamento por co-mistura e por inserção sugere um sistema de identidade, de cultura e de territorialidade política que pode iluminar o vínculo entre o fundamento local e o prospecto de globalização.

O entrelaçamento por sobreposição e por co-mistura nasce comumente de encontros serendipitosos entre indivíduos ou grupos, e expressa uma vaga reorientação ou recombinação no interesse. O entrelaçamento não resulta de um projeto ou programa preestabelecido. A pesquisa na física dos sólidos, desenvolvida na França logo após o final da Segunda Guerra Mundial, por meio das iniciativas de cientistas tais como L. Néal, J. Friedel, P. Aigrain, A. Guinier e R. Mastain, concentrou-se nos semicondutores baseados em substâncias puras sem defeito. Ela incluiu trabalho sobre a 
supercondutividade e o magnetismo (cf. Pestre, 2001). Durante os anos 1970, emergiu uma corrente de pesquisa adicional que tratava de materiais porosos, cristais líquidos e substâncias com defeitos. Essa reorientação teve como pioneiro Pierre-Gilles de Gennes, que fundou uma escola de pesquisa de "soft materials" e que recebeu o Prêmio Nobel, em 1991, por suas contribuições coletivas. Essa nova direção não tinha embasamento disciplinar ou institucional. Seu ponto focal era os meios aleatórios macroscópicos (milieux aléatoires macroscopiques) - o estudo de materiais desordenados enquanto oposto à análise física anterior dos materiais puramente cristalinos, não defeituosos - de onde surgiu o acrônimo MIAM, assumido pelo grupo de entrelaçamento. Materiais macroscópicos desordenados constituíam seu objeto de investigação. O que incluía fenômenos de suspensão, gelatinização, percolação e o crescente estudo de fluidos e materiais secos granulares e porosos. Enfatizou-se temas como ruptura e desgaste. Os fractais e a não-linearidade constituíam as ferramentas conceituais rotineiras. Um tema então recorrente era a transição de fase (liquido/gás). Esses tópicos compartilham um estilo comum de trabalho. A pesquisa não somente cobria uma diversidade de entidades físicas, mas também envolvia uma gama de atores disciplinares, estendendo-se da mecânica de fluídos à química, à cerâmica, à metalurgia, à estatística, à geofísica, à ciência dos materiais, às ciências da Terra, à simulação, à engenharia etc. O domínio inicial sugeria possíveis aplicações importantes; alguns grupos industriais cruzaram a fronteira academia/empresa e participaram do entrelaçamento por sobreposição. ${ }^{\mathbf{2}}$ Empresas como Saint Gobain, Lafarge Rhône Poulenc e IFP participaram da nova pesquisa não-estruturada, embora intensa, sobre materiais desordenados.

O campo foi, já no início, altamente louvado com o Prêmio Nobel de Física, conferido em 1977 a Philip W. Anderson por seu trabalho sobre "localização". Anderson imediatamente percebeu que o mais leve defeito qualitativo em uma substância transforma o comportamento físico dessa substância. Desse modo, surgia uma abertura para um campo completamente novo de investigação, não coberto por qualquer disciplina ou instituição. O empenho nesse campo constituía, assim, uma questão de entrelaçamento, o que possibilitou tanto a indivíduos como a grupos reterem seu referente cognitivo e organizacional de base, enquanto permitia, ao mesmo tempo, a circulação por meio da sobreposição e da co-mistura de cientistas da mesma disciplina, ainda que de instituições diferentes e que compartilhavam o mesmo interesse, ou ainda de cientistas de disciplinas alternativas que compartilhavam preocupações todavia aná-

8 Um exame cuidadoso revela, não obstante, que esse entrelaçamento era, de fato, limitado a uma sobreposição e não se constituía como um entrelaçamento por co-mistura. As razões para essa inibição podem ter sido a restrição ao direito de propriedade ou, de outro modo, o fracasso em obter resultados financeiros suficientemente rápidos na forma de lucro empresarial. 
logas, fundadas na mesma instituição. A fluidez da pós-modernidade não foi requerida para a realização do entrelaçamento, e as restrições ao modelo da modernidade flanqueada foram obliteradas pelas práticas e pela comunicação do entrelaçamento.

Em 1978, foi organizado um seminário pelos físicos franceses P. G. de Gennes, E. Guyon e seus colegas, na famosa sala de conferência em Les Houches, para apresentação de trabalhos sobre materiais defeituosos e desordenados. A iniciativa foi apoiada pela seção de Química do Centre National de la Recherche Scientifique (CNRS). Dúzias de cientistas assistiram, não exclusivamente oriundos da França. Numerosas disciplinas foram representadas e os tópicos centraram-se sobre fenômenos de suspensão e de gelatinização. Em 1980, em um outro seminário de verão em Les Houches, E. Guyon apresentou uma comunicação sobre médias randonômicas macroscópicas. Nessa juntura, o caráter de entrelaçamento do movimento tornava-se manifesto. Enquanto um laboratório parisiense e outro em Rennes e em Marselha administravam a parte organizacional, muitos indivíduos assistiram a uma sucessão de seminários não enquanto representantes de seus institutos oficiais, mas como indivíduos ou grupos que desejavam entrelaçar-se, por sobreposição ou por co-mistura, em uma base mais estável, mesmo oficial, com colegas provenientes de outras especialidades ou institutos de pesquisa. Colaboração e sinergia constituíam o objetivo. O CNRS aceitou fornecer certo apoio. Proveu-se uma série de fundos modestos, topicamente centrados, para temas particulares, na forma de uma Ação Temática Programada. Entretanto, uma vez que se tornava cada vez mais manifesto o entrelaçamento por sobreposição e por co-mistura de investigadores das nações vizinhas (Inglaterra, Alemanha, Noruega e Estados Unidos), o CNRS optou por estender a ajuda. O fundo da Ação Temática Programada tornou-se, assim, cada vez mais disponível e, nos anos de 1990, dois financiamentos quadri-anuais foram designados para o grupo de pesquisa. É importante notar que os últimos programas não foram particularmente designados para os fundos de pesquisa. Tais fundos constituem especificamente motores do entrelaçamento, notadamente um entrelaçamento por sobreposição e co-mistura. Eles oferecem recursos para viagens, para a comunicação e para estudantes de doutorado e de pós-doutorado. Essas iniciativas são de importância central para o entrelaçamento. Contudo, o movimento é percebido a partir do interior da perspectiva dos referentes estabelecidos.

O exemplo brevemente descrito do MIAM oferece indicações acerca de como os referentes do entrelaçamento operam, na forma de disciplinas, institutos de pesquisa e instituições nacionais. O entrelaçamento por sobreposição e co-mistura permite a extensão de técnicas novas ou emergentes, de questões, de estilos de trabalho e, acima de tudo, de padrões e, algumas vezes, de continuidades de circulação. No entrelaçamento por co-mistura, como se observa no entrelaçamento das relações não oficiais entre Paris, Rennes e Marselha, ocorre uma sinergia de longo prazo que continua a 
persistir no interior de um entrelaçamento - contrariamente ao que ocorre em uma estrutura institucionalizada -, no qual, por um lado, colaborações e sinergia, breves ou duradouras, existem independentemente da inercial tendência institucional da modernidade, ou mesmo da indiferença, ou, por outro lado, da total ausência dos requerimentos da pós-modernidade para escapar da interminável fluidez e ausência de fronteiras. 9

O segundo exemplo de entrelaçamento concreto trata com o entrelaçamento por co-mistura e inserção, particularmente com referência à globalização. Embora a globalização seja um objetivo proeminente para muitos pós-modernos, existe pouca discussão acerca de como a globalização deve ser alcançada. A discussão se coloca em termos da supressão do Estado-nação, do capitalismo monopolista, da emergência das corporações multinacionais, da cidadania mundial e da fluidez - ainda que estes possam ser vistos como fins, antes que como meios. Em alguns casos, a questão das relações entre o local e o global é levantada, mas deixa-se em silêncio, uma vez mais, as interconexões e mecanismos precisos no equilíbrio entre o local e o global. Irei sugerir, em seguida, que combinações de entrelaçamento de sobreposição e entrelaçamento por co-mistura representam uma base para a formação de territórios. Por sua vez, o entrelaçamento por sobreposição e co-mistura pode, assim, estender territórios em direção à globalização. A centralidade da escala local repousa particularmente em sua íntima e autêntica conexão com os habitantes autóctones e com a comunidade. Essa fixação no local é histórica, cultural, econômica, política e lingüística. O entrelaçamento por sobreposição fornece uma lógica para a dinâmica local. A concatenação entre local e territorial pode ser promovida por meio de uma combinação de entrelaçamentos por sobreposição e por co-mistura, assim como localidades múltiplas podem construir mecanismos aditivos de interesse, de mito, de instrumentalidade e de migração. A co-mistura bem pode se mostrar particularmente decisiva aqui. A juntura

9 Cf. Shinn \& Marcovich, no prelo. Nesse artigo, os autores apresentam três configurações de laboratórios contemporâneos de pesquisa. Uma dessas configurações é a configuração "porosa”; ela é emblemática de um entrelaçamento por sobreposição. Descreve-se um laboratório marginalmente institucionalizado do GNRS, cujos objetivos nunca foram divulgados ou esclarecidos, e se associa esse laboratório com a procura pela matéria escura. Na realidade, a investigação da matéria escura tornou-se um centro para o entrelaçamento por sobreposição relacionado ao magnetismo, à sismologia, a fenômenos atmosféricos selecionados, aos estudos cósmicos e à mecânica. Cientistas e engenheiros permaneceram vinculados aos seus institutos oficiais de pesquisa no CNRS e às suas respectivas disciplinas. Eles também se encontram de modo intermitente no pólo de entrelaçamento onde eles atravessam principalmente fronteiras em termos de compartilhamento e construção de nova expertise técnica. Não existe hibridização alguma, nem qualquer fluidez. Esse entrelaçamento por sobreposição tampouco gera fechamentos do tipo que os modernos talvez considerem inevitáveis. O entrelaçamento por sobreposição favorece a comunicação, o compartilhamento de materiais e, às vezes, as colaborações práticas. O entrelaçamento ainda mostra-se constituir um mecanismo elástico e flexível para o estabelecimento e também para a modificação dos graus de interação entre indivíduos e grupos conscientes da vantagem da cuidadosa mobilidade definida. Isso não constitui nenhum nomadismo pós-moderno, mas antes a circulação seletiva no interior de um território demarcado de modo múltiplo. 
territorial e a projeção em direção à globalização podem ter uma base no entrelaçamento por inserção. Essa concatenação de diversos entrelaçamentos oferece uma dinâmica de multi-nível e de multi-referente em direção à globalização. A perspectiva da matriz de entrelaçamento merece ser considerada de acordo com três bases principais. Primeiro, ela preserva a autenticidade/autoctonia local em face ao global. Segundo, ela situa os territórios no centro do localismo transversal. Terceiro, ela permite o dinamismo e a reversibilidade nas batalhas e confrontos entre programas culturais e políticos alternativos de organização da humanidade. Oferece, pelo menos, uma resposta à questão bastante legítima de R. Lee no debate modernidade/pós-modernidade, ou seja, qual é o lugar da modernidade local múltipla na arquitetura da evolução cognitiva e social, particularmente em relação à globalização do mundo em desenvolvimento no hemisfério sul? Parte da resposta pode residir na matriz de entrelaçamento.

Os contornos daquilo que constitui o "local" são bastante familiares. Considerações de família, clã e tribo eram bastante centrais, e atualmente o grupo local está organizado em torno de escolas, do esporte, de associações em apoio aos times locais, de causas e grupos cívicos, de atividades culturais etc. A geografia também é de central importância para a escala local. O local freqüentemente coincide com caminhos de comunicação e de transporte através de rios ou ao redor de lagos, que se acomodam sobre vales ou em planícies determinadas por cadeias de montanhas etc. As economias locais produzem uma gama de produtos autônomos, o que é necessário para a sobrevivência local; existe um circuito local de troca e intercâmbio, e não é raro a existência de um idioma ou dialeto local - o córsico, o bretão, o alsaciano etc., ficando apenas com os encontrados na França. As catástrofes locais são vividas e compartilhadas como eventos históricos, e personalidades históricas carismáticas surgem, podendo incorporar-se na paisagem do mito heróico.

A própria força do local constitui um entrelaçamento por sobreposição. Tal entrelaçamento traz os indivíduos para junto das comunidades e da diversidade de atividades que compõem o local. Ele permite a mobilidade e a extensão no interior do local. Por meio dos mecanismos e da dinâmica do entrelaçamento por sobreposição, os indivíduos podem reter seu referente básico, bem como permanecer no interior do ambiente local quando se requer a mudança para um referente alternativo. Oportunidades de emprego inconstantes são freqüentemente identificadas e localmente obtidas por meio do entrelaçamento de sobreposição. Por força desse entrelaçamento de sobreposição, o referente principal permanece sendo o local, ainda que indivíduos e grupos possam circular e mudar, adquirir novas habilidades, acumular novas realizações e misturar-se com novos grupos na familiaridade e segurança do ambiente circunscrito de casa. 
O desafio difícil consiste no movimento da escala local para a dimensão territorial. ${ }^{10} \mathrm{Um}$ território pode simplesmente ser visto como uma reunião ou combinação de múltiplos locais. De modo alternativo, um território pode ser visto como constituindo um elemento adicional que transcende meramente um agrupamento de diversas localidades. Ele pode ser percebido como oferecendo um valor agregadoum potencial novo e adicional que ultrapassa a simples adição de uma série de ambientes locais. Enquanto a lógica de entrelaçamento do local é principalmente a do entrelaçamento por sobreposição, o entrelaçamento suportado por um território é o entrelaçamento por co-mistura e, em menor extensão, talvez também o entrelaçamento por inserção.

Um território transcende seus componentes locais. Ele requer um entrelaçamento por co-mistura na forma de pessoas que respeitam e compreendem as particularidades do referente local, e que também falam um idioma transversal, que desfrutam de conhecimento transversal e que possuem uma visão transversal que reconhece a entidade territorial. Não existe aqui necessidade alguma de os atores do entrelaçamento por co-mistura abandonarem seus referentes locais autóctones. Para esse referente local, os atores multiplicam sua competência por meio de recursos suplementares de referentes locais. Por meio da sinergia, esse entrelaçamento profissional, cognitivo e social alcança os benefícios associados com a territorialidade transversa multi-local.

Ademais, a territorialidade baseia-se na geografia, na economia e na história. Ela compartilha necessariamente uma moeda comum e, até certo ponto, um conjunto comum de valores, de ambições políticas e, eventualmente, de instituições políticas. De modo semelhante, mitos e símbolos territoriais necessariamente emergem. Os territórios estão, assim, fisicamente conectados. Eles podem construir uma história e uma mitologia convergentes. Eles identificam e inventam os entrelaçamentos por co-mistura que, ao mesmo tempo, permitem e legitimam seus projetos territoriais. A territorialidade não é uma unidade social "natural" do mesmo modo que a escala local. Em vez disso, ela é freqüentemente uma combinação de conexões comerciais, de circulação da produção e de cálculo político. E para a vida se expressar em uma unidade territorial, a consciência e o entrelaçamento estratégico devem se desenvolver. As fluididades e a anti-diferenciação da pós-modernidade fecham o caminho para o território. Elas favorecem a anti-territorialidade, a fragmentação, a hiper-diversidade e a diferença. O território é um produto de junturas no interior do local; e, assim, sua conjunção e formas de entrelaçamento figuram aqui relevantes na forma de indivíduos que atravessam localidades e se co-misturam com numerosos referentes no interior de 
uma noção mais abrangente de território. Com efeito, o entrelaçamento por co-mistura oferece uma matriz estável para a construção e para a arquitetura de um território.

Por fim, como explicar o sonho pós-moderno de globalização? Como já indicado, o processo recebeu pouca atenção, e desde que a pós-modernidade nega a estrutura e a função, os contornos da globalização pós-moderna também permanecem encobertos. Se a fluidez, a anti-diferenciação e a diferença individual fragmentada constituem a totalidade da globalização, então existe pouco mais a se dizer. Por outro lado, se a globalização pretende, em vez disso, representar algo substantivo, o entrelaçamento pode ser relevante, em particular, o entrelaçamento por co-mistura e o entrelaçamento por inserção.

A globalização pós-moderna pode, com efeito, sinalizar a comunicação e a troca econômica livre de tarifa. Poder-se-ia até mesmo aludir a uma única moeda corrente. É improvável, entretanto, que isso se estenda a uma fluidez desimpedida de populações de todas as raças, classes e habilidades, como se evidencia por inumeráveis eventos históricos contemporâneos - muitos dos quais trágicos, para dizer o mínimo. Todavia, se um tipo de semi-globalização é seriamente esperado ou antecipado, o entrelaçamento por inserção poderia desempenhar um papel. O entrelaçamento por inserção, nesse contexto, poderia promover o envolvimento do indivíduo e do grupo em um referente territorial, antes que em um referente local. A globalização envolveria a convergência e conexão de múltiplos territórios, mas talvez não a totalidade dos territórios dos planetas. Assim, o entrelaçamento por inserção poderia percorrer múltiplos territórios. Uma vez que se toma um território como o referente central, o atravessar de fronteiras para outros territórios, acompanhado por conhecimento apropriado e prática multi-territorial, e que se baseia em permanências amplas, poderia contribuir para a introdução de confiança recíproca, de representações, modos de interação e a preparação de uma pragmática multi-territorial e mesmo de regras que poderiam promover uma forma bondosa de globalização. O entrelaçamento por inserção não pretende - com efeito, assim como nenhuma categoria de entrelaçamento - produzir a homogeneidade, a conformidade etc. Ao contrário, a missão do entrelaçamento é a preservação de habilidades e representações heterogêneas, com a possibilidade de promover combinações novas, re-combinações e, potencialmente, des-combinações. No cenário da globalização pós-moderna, portanto, a vocação do entrelaçamento seria uma abertura em direção a uma confederação - e mesmo a uma federação - mais abrangente, mesmo em um contexto no qual a circulação maximal e a sinergia são protegidas e fundadas na cultura, em hábitos e em especializações locais ou territoriais.

A auto-contradição da pós-modernidade consiste em que esta evoca a onipresença de um padrão. A dinâmica de cada uma das três formas de entrelaçamento é bastante distinta. $\mathrm{O}$ entrelaçamento privilegia referentes definidos e delimitados, 
promovendo uma travessia de fronteira seletiva e propositada em direção aos referentes alternativos, em vista da realização de objetivos cognitivos, epistemológicos ou sociais, embora sempre mantendo contato com o referente originário e conservando espaço para a manobra em vista da des-combinação, assim como também para a combinação ou a re-combinação na busca pela novidade.

\section{OBSERVAÇÕes FINAIS}

A introdução do conceito de "entrelaçamento" em conexão com o conceito de "referente" e a operacionalização de três formas de entrelaçamento ("por sobreposição", "por co-mistura" e "por inserção") tem a intenção de fornecer uma perspectiva alternativa para o exame do material cognitivo, epistemológico e das transformações sociais dos últimos 50 anos - e talvez mesmo mais que isso. O debate modernidade versus pós-modernidade, embora tenha produzido uma riqueza de escritos e numerosos pensamentos originais e, às vezes, interessantes, está tornando-se repetitivo e, em certas ocasiões, trivial. Embora a perspectiva da modernidade tenha representado compreensivamente muitos eventos que ocorreram entre o século xvir e meados do século $\mathrm{xx}$, é evidente que, por uma variedade de razões muitas vezes obscuras, transformações importantes modificaram a cognição, a epistemologia, os materiais e a sociedade durante as últimas décadas.

Alguns estudiosos têm buscado desesperadamente revisar a análise da modernidade a fim de explicar essas transformações, e algumas tentativas têm sido freqüentemente cogitadas. Outros escritores abandonaram completamente as teses da modernidade e, assim, têm reescrito a experiência humana em termos de pós-modernidade. Eles procuram descrever um mundo marcado pela completa descontinuidade com a história pregressa e tentam explicar essa nova orientação. Examinado a partir de uma perspectiva puramente filosófica, poder-se-ia pensar que a colocação modernidade versus pós-modernidade inclui uma dinâmica dialética hegeliana de tese e antítese! Contudo, não está absolutamente claro até que ponto tais escritos pós-modernos refletem genuinamente a mudança ou, de outro modo, em que grau eles encerram uma nova representação fundada no ceticismo e em sofismas. A resposta conveniente situa-se provavelmente em algum lugar intermediário. Seja como for, algumas autoridades pós-modernas mais parecem expressar o desejo para produzir surpresa e clamor do que contribuir para uma análise cuidadosa que respeita a metodologia, o rigor e as condições limitantes. A onipresença do vocabulário da "reflexividade", em uma miríade de formas mal definidas ou contraditórias, é emblemática do desejo da pósmodernidade de fundar seu discurso e formular soluções para problemas sociais ou 
catástrofes que são freqüentemente produzidos. Defensores da modernidade, de uma ou de outra opinião, apelam similarmente, de modo não crítico, à "reflexividade" - ou para enriquecer seu próprio discurso emblemático ou para criticar os pós-modernos. O léxico do debate modernidade versus pós-modernidade é, assim, freqüentemente deficiente e exibe uma pobreza de imaginação.

A ambição do presente artigo foi representar criticamente o pensamento moderno e pós-moderno, acrescentando alguns exemplos para apontar falhas salientes em ambos os campos. A apresentação da noção de entrelaçamento foi empregada como um veículo crítico. Entretanto, além disso, o conceito de entrelaçamento pode também oferecer um caminho de reflexão capaz de contribuir para evitar o debate modernidade versus pós-modernidade. Em relação à noção de "entrelaçamento", talvez agora seja o momento para o desenvolvimento de uma exploração sistemática de uma filologia de um agrupamento de linguagem que incorpora uma família de termos, tais como "entrelaçamento", "sobreposição", "co-mistura", "inserção", "cooperação", "circulação" e "sinergia". Essa filologia oferece enormes contrastes com a linguagem tanto da modernidade como da pós-modernidade. Isso é manifesto a partir de um rápido relance por sobre os léxicos centrais da análise social contemporânea dominante e pós-dominante. Uma sistemática abordagem filológica pode iluminar profundamente as consolidadas conexões envolvidas na terminologia proposta pela abordagem de entrelaçamento e também sugerir novas interpretações a essa filologia, evocando, assim, novas trajetórias de significado.

Com efeito, é possível que nem a modernidade nem a linha pós-moderna de pensamento capturem adequadamente a experiência cognitiva, epistemológica e social contemporânea. Podemos estar nos movendo em direção a uma pós-pós-modernidade, e a perspectiva do entrelaçamento, assim como sua filologia auxiliar, pode articular modestamente alguns aspectos desse novo e necessário modo de ser e de pensar.

Traduzido do original em inglês por Pablo Rubén Mariconda \& Guilherme Rodrigues Neto

Terry SHInN

Pesquisador do GEMAS (UMR 8598), Maison des Sciences de l'Homme de Paris, França. shinn@msh-paris.fr 


\begin{abstract}
AB STRACT
In many significant quarters, the tone and substance of sociological discourse on the past, present and future of culture at large, institutions, content of individual pursuits and relations, and about the matter and organization of science, technology and epistemology has changed appreciably. Post-modern society discourse, and correspondingly supportive intellectual and social phenomena, offer some credence to arguments that the world of today and the prospects of tomorrow stand in radical contrast or even asymmetry with the world of the past two and a half centuries. The purpose of this article is threefold. First, it is necessary to identify the specific domains in which post-modern claims differ from dominant notions of the modernity representation of society and science. In what ways do post-modernity portrayals substitute and repudiate modernity concepts, and alternatively, to what degree do they instead seek to build on them taking into account recent cognitive, technological and societal shifts, yet still within a modernity framework? Second, what constitutes the foundational cultural and cognitive message of post modernity? Where does the message authentically break with modernity, and where does it distinctly seek to destroy the very foundations of modernity thinking? What are the putative implications for science, technology, and for epistemology itself? Finally, an alternative to post-modern analysis will here be advanced, an alternative that draws on basic features of modernist thinking, yet which incorporates events that have undeniably transform man, machine, material and epistemology over the last several decades, and which thus redraws the modernity map by specifying alternative components and modes of interaction and extension. This hypothesis may be interpreted as a bridge and deviation from both classical and post modernity. This line of thought may be clumsily labeled for the moment "post post modernity". The hypothesis is ground on an "interlacing matrix". This interlacing matrix mobilizes three fundamental notions which are strongly informed by contemporary experience in science and technology, although not exclusively from those domains. The pivotal place accorded here to learning and epistemology is not unwarranted, in view of their primacy in today's stream of action (innovation, daily life, and politics).
\end{abstract}

KeYwords $\bullet$ Post modernity. Modernity. Weber. Lyotard. Jameson. Beck. Gibbons. Durkheim. Interlacing matrix.

\title{
REFERÊNGIAS BIBLIOGRÁFIGAS
}

Аввотт, A. Things of boundaries. Social Research, 62, 4, p. 857-82, 1995.

BECK, U. The theory of reflexive modernization: problematic, hypotheses, and research program. Theory, Culture and Society, 20, 1, p. 1-33, 2003.

Beck, U.; Giddens, A. \& Lash, S. (Ed.). Reflexive modernization: politics, tradition and aesthetics in the modern social order. Stanford: Stanford University Press, 1994.

Bourdieu, P. La distinction: critique sociale du jugement de gout. Paris: Minuit, 1979.

Castells, M. The rise of the network society. Oxford: Blackwell, 1996.

Durкheim, É. The elementary forms of religious life. New York: The Free Press, 1912. The division of labor in society. New York: The Free Press, 1993.

Elias, N. La société des individus. Paris: Fayard, 1987.

Espeland, W. \& Mitchel, S. Commensuration as a social process. Annual Review of Sociology, 28, p. 313$4,1998$.

Etzkowitz, H. \& LeydesdorfF, L. Universities and the global knowledge economy: a triple helix of universityindustry-government relations. London: Cassell Academic, 1997. 
Forman, P. Weimar culture, causality, and quantum theory: adaptation by German physicists and mathematicians to a hostile environment. Historical Studies in the Physical Sciences, 3, p. 1-115, 1971.

. The primacy of science in modernity, of technology in post modernity, and of ideology in the history of technology. History of Technology, 23, 1-2, p. 1-152, 2007.

Gibвоns, M. et al. The new production of knowledge: the dynamics of science and research in contemporary societies. London: Sage, 1994.

Giddens, A. Modernity and self-identity. Cambridge: Polity, 1991.

. Living in a post-traditional society. In: BeCK, U.; Giddens, A. \& Lash, S. (Ed.). Reflexivemodernization: politics, tradition and aesthetics in the modern social order. Stanford: Stanford University Press, 1994. p. 56-109.

Habermas, J. The political discourse of modernity. Cambridge: MIT Press, 1987 .

IngLis, D. Confronting culture: sociological vistas. Cambridge: Polity, 2003.

Confronting everydaylife. London: Routledge, 2005.

IngLis, D. \& Bones, J. Boundary maintenance, border crossing and the nature/culture divide. European Journal of Social Theory, 9, 2, p. 272-87, 2006.

Jameson, F. Post modernity: or the cultural logic of late capitalism. London: New Left Review, 1984.

Lash, S. Aesthetic reflexive modernization: the aesthetic dimension. Theory, Culture and Society, 10, 1, p. 1-24, 1993.

. Reflexive and its doubles: structure, aesthetics, community. In: BeCK, U.; Giddens, A. \& LASH, S. (Ed.). Reflexive modernization: politics, tradition and aesthetics in the modern social order. Stanford: Stanford University Press, 1994. p. 110-173.

Lash, S. \& Friedman, J. Sociology of post modernity. London: Routledge, 1990 Modernity and self-identity. Cambridge: Polity, 1992.

Lash, S. \& Friedman, J. (Ed.). Modernity and identity. Oxford: Blackwell, 1992.

Latour, B. Science in action: how to follow scientists and engineers through society. Cambridge: Harvard University Press, 1987.

. Nous n'avons jamais étémodernes: essai d'anthropologie symétrique. Paris: La Découverte \& Syros, 1997. . Is re-modernization occurring - and if so, how to prove it? A commentary on Ulrich Beck. Theory, Culture and Society, 20, 2, p. 35-4,8, 2003.

Latour, B. \& Woolgar, S. Laboratory life: the construction of social scientific facts. Los Angeles/London: Sage, 1979 .

LEE, R. In search of second modernity: reinterpreting reflexive modernization in the context of multiple modernities. Social Science Information, 47, p. 47-55, 2008.

Luhman, N. The modernity of science. New German Critique, 61, p. 9-16, 1994.

Lyotard, J. F. La condition postmoderne, rapport sur le savoir. 1979. Paris: Minuit, 1979.

Le différent. Paris: Minuit, 1983.

. Le postmoderne expliqué aux enfants. Paris, Edition Galilée, 1988.

Marcovich, A. A quoi rêvent les sociétés? Paris: Odile Jacob, 2001.

Nowotny, H. et al. Re-thinking science. Knowledge and the public in an age of uncertainty. Oxford: Polity, 2001.

Pestre, P. Physique et physiciens en France 1918-1940. Paris: Archives Contemporaines, 2001.

RAsch, W. Theories of complexity, complexity of theories: Habermas, Luhman and the study of social systems. German Studies Review, 14, 1, p. 65-83, 1999.

Scoтt, A. Modernity's machine metaphor. British Journal of Sociology, 48, 4, p. 561-75, 1997.

Shilling, P. \& Mellor, C. Durkheim, morality and modernity: collective effervescence, homo duplex and the sources of moral action. The British Journal of Sociology, 49, 2, p. 193-209, 1998. 
Desencantamento da modernidade e da Pós-Modernidade...

Shinn, T. Savoir scientifique et pouvoir social: l'école polytechnique, 1793-1914. Paris: Sciences Politiques, 1980.

. The triple helix and new production of knowledge: prepackaged thinking on science and technology. Social Studies of Science, 32, 4, p. 599-614, 2002.

.When is simulation a research-technology? Practices, markets, and lingua franca. In: LenHARd, J.; KüPPERs, G. \& Shinn, T. (Ed.). Simulation, pragmatic construction of reality. Springer: Dortrecht, 2006. p. $187-203$.

Shinn, T. \& Lamy, E. Caminhos do conhecimento comercial: formas e conseqüências da sinergia universidade-empresa nas incubadoras tecnológicas. Scientiae Studia, 4, 3, p. 4.85-508, 2006.

Shinn, T. \& Marcovich, A. Cognitive/organisational blocks. Promethean, territorial and porous configurations. Social Science Information, 1, 2009. No prelo.

Shinn, T. \& Ragouet, P. Controverses sur la science: pourune sociologie transversaliste des activités scientifiques.

Paris: Raison d'Agir, 2005.

Stein, W. The end of what modernity? Theory and Society, 24, 4, p. 471-88, 1995.

VeYne, P. Foucault, sa pensée, sa personne. Paris: Albin Michel, 2008.

WEBER, M. The protestant ethic and the spirit of capitalism. London: George Allen and Underwin, 1993. A ética protestante e o "espirito" do capitalismo. São Paulo: Companhia das Letras, 2004.

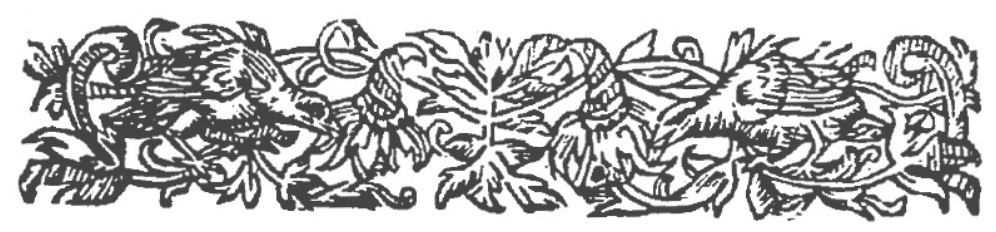

